\title{
Sobre la identificación macroscópica de las piezas astilladas: propuesta experimental
}

\author{
The macroscopic identification of splintered pieces: an experimental proposal
}

Paloma de la Peña Alonso (*)

\section{RESUMEN}

El morfotipo lítico "pieza astillada" (pièces esquillées o splintered pieces) ha sido relacionado, por los estudios de Prehistoria, con dos actividades muy distintas: la talla posada sobre yunque -también denominada "talla bipolar"- y el empleo de piezas intermedias - a modo de cuña/cincel- para el trabajo de materias primas duras (hueso, madera y asta). Se presenta una propuesta experimental que busca distinguir macroscópicamente estos dos tipos de actividades y discernir en qué casos se produce o no lo que tipológicamente se considera "pieza astillada". Se concluye con una descripción detallada de las macrotrazas obtenidas para cada una de las variantes de la experimentación, en la que se especifica qué casos reproducen lo que tipológicamente denominamos "pieza astillada".

\begin{abstract}
Splintered pieces have been linked in different studies with two activities: bipolar flint knapping and the use as an intermediate tool (i.e. wedges) for working hard materials (e.g. bone, wood and antler). The aim of this experimental study was to distinguish macroscopically the characteristics of pieces resulting from both processes and moreover, to discern clearly in which circumstances what are considered typologically splintered pieces are produced. The study is concluded with a detailed description of the macro-traces associated with each of the experimental procedures performed and which define the actions that led to typologically characteristic splintered pieces.
\end{abstract}

Palabras clave: Pieza astillada; Cuña; Talla bipolar; Arqueología experimental; Traceología.

(*) Dpto. de Prehistoria. Facultad de Geografía e Historia. Universidad Complutense de Madrid. Av. del Profesor Aranguren s/n. 28040, Madrid. Correo e.: palomap@ghis.ucm.es

Recibido: 3-I-2010; aceptado: 26-III-2010.
Key words: Splintered piece; Wedge; Bipolar flaking; Experimental Archaeology; Traceology.

\section{INTRODUCCIÓN}

Las piezas llamadas "astilladas" constituyen un morfotipo lítico conocido desde el comienzo de la disciplina de la Prehistoria, cuya primera definición acuñaron L. Bardon, A. y J. Boussonye (1906). Estos autores pensaron que se trataban de útiles obtenidos mediante la talla por percusión directa de fragmentos de sílex posados sobre un yunque y, por tanto, que el objetivo para estas herramientas eran los filos que quedaban entre los dos extremos percutidos. Desde entonces, las piezas astilladas (pièces esquillées o splintered pieces) han sido identificadas de manera recurrente en los conjuntos líticos de diferentes épocas del Paleolítico Superior inicial (Zilhão 1997; Aubry et al. 1998; Gibaja y Bicho 2006) y final (Leesch 1997; Cattin 2002; Clottes y Delporte 2003), e incluso de períodos posteriores (Rodríguez 1993; Furestier 2005; Cabanilles 2008, etc.)

Desde las primeras publicaciones ya se apuntan diferentes hipótesis con respecto a su significado o posible funcionalidad. Así, se interpretan como "piedras de fuego", puesto que su morfología es idéntica a la producida por el golpe entre dos sílex para producir chispas (Brézillon 1971). Según C. Octobon (1938) podían ser útiles para trabajar materias duras o quizá núcleos para obtener lascas, hipótesis retomadas posteriormente en múltiples ocasiones (Binford y Quimby 1963; Escalon de Fonton 1969; Mazière 1984, entre otros). 
A finales de los años 1950, la pièce esquillée fue incluida en la lista-tipo de Sonneville-Bordes y Perrot (1956: 552), descartando la propuesta sobre su posible identidad como núcleos: Piéce géneralement rectangulaire ou carrée présentant sur les deux bouts, plus rarement sur les quatre côtés, des esquillements parfois bifaciaux obtenus par percusión violente.

S. A. Semenov (1964: 145-160), en su obra Lithic tecnology, alude también a estas piezas, aunque desde otros planteamientos. Considera que se utilizarían probablemente como cinceles para trabajar hueso y madera, siendo éstas las pièces écaillées definidas por la bibliografía francesa.

Posteriormente, J. Tixier señala que este morfotipo posee un peso notable en los conjuntos del Epipaleolítico y del Iberomauritano del Maghreb. Descarta de partida una hipótesis anterior que lo contemplaba como percutor intermedio para la talla (chasse-lame o punch), o como fruto de la talla bipolar, pese a reconocer que las trazas que deja dicho método son idénticas (Tixier 1963: 147). Sugiere, sin embargo, que para los conjuntos epipaleolíticos del Maghreb no son útiles con una morfología especialmente buscada, sino fruto de su propia utilización, es decir, piezas con retoque a posteriori, quizás empleadas sobre materiales perecederos. Tixier define además tres fases en su utilización (Fig. 1).

Durante los años 1970 las piezas astilladas son excluidas de la lista-tipo en el Coloquio de Talence (Sonneville-Bordes 1979), dada la dificultad, al parecer, de proponer una estricta definición tipológica; quizás porque se consideraban como "útiles" a posteriori (Bordes, 1970), pues no portaban las "trazas" de su fabricación (façonnage), sino de su posible utilización, como ocurría con las pièces machurées. Sin embargo, la nueva propuesta tipológica de G. Laplace (1972) resaltó su importancia, incluyendo al nuevo "modo" astillado y, al mismo tiempo, al orden de los astillados. No obstante, tampoco en su tipología se abordó su posible significado tecnológico o funcional.

En los años 1970 y 1980, la bibliografía norteamericana planteó varias hipótesis en cuanto a su verdadera finalidad, fundamentadas en gran medida en trabajos experimentales con talla bipolar y en estudios etnoarqueológicos. Los autores anglosajones centraron el debate sobre su supuesto origen a partir de la talla bipolar o talla posada sobre yunque, y no tanto en su posible funcionali-

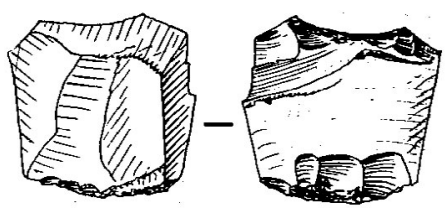

$1^{\text {a }}$ Fase: extremos astillados, sin estigmas de levantamientos invasores. Anverso y reverso en gran parte intactos.

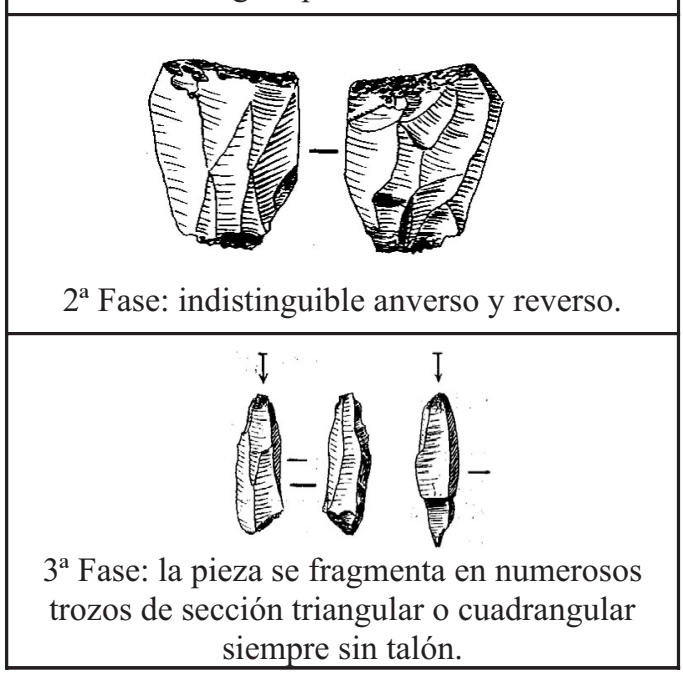

Fig. 1. Fases de reducción de piezas astilladas empleadas como cuñas, modificado de Tixier (1963: 148-149).

dad. P. White (1968a, 1968b) describe la talla bipolar a partir de trabajos etnológicos en Nueva Guinea y considera que las splintered pieces arqueológicas australianas pueden ser el resultado del mismo método de talla. Asimismo, se discute la posibilidad de que la talla bipolar sea un método de producción de soportes controlable (Patterson y Sollberger 1976). Dentro de estos trabajos B. Hayden (1980) tuvo la virtud de llamar la atención, por primera vez, sobre la confusión entre pièces esquillées (piezas astilladas) y bipolar cores (núcleos bipolares). En dicho artículo señalaba que morfologías aparentemente similares son confundidas e identificadas con dos actividades completamente distintas. Para Hayden, las pièces esquillées son útiles destinados a trabajar materiales duros perecederos, abundantes en los sitios paleolíticos franceses, mientras que el objetivo de los núcleos bipolares es producir soportes líticos. Aunque B. Hayden apuntó el problema y describió algunos estigmas para estas dos casuísticas, no aclaró del todo su distinción. Una de las sínte- 
sis más completas sobre las piezas astilladas es la de Chauchat et al. (1985) que plantea la dificultad de distinguir si son útiles a posteriori, núcleos bipolares para obtener soportes o, incluso, las dos hipótesis anteriores juntas, útiles obtenidos por percusión bipolar para lograr dos filos opuestos cortantes.

Las propuestas posteriores sólo reinciden sobre las hipótesis previas (Shott 1989; Leblanc 1992; Googyear 1993). De hecho, generalmente se les atribuye alguno de estos roles y más bien por intuición que por contrastación. Así, en algunos sitios magdalenienses las piezas astilladas se suelen asociar al trabajo de materiales duros como el asta, pese a que no se argumente dicha asociación (por ejemplo Leesch 1997: 111-112). Por otra parte, la hipótesis que vincula su origen con la talla bipolar también se ha retomado. Un buen ejemplo de ello son los sitios gravetienses portugueses de Buraca Escura y Buraca Grande (Aubry et al. 1998), para los que se ha propuesto dos tipos de cadenas operativas destinadas a la obtención de hojitas, una basada en piezas carenadas y la otra en la percusión posada sobre yunque o talla bipolar asociada a piezas astilladas.

La confusa definición de estas piezas y su recurrente aparición en conjuntos de Paleolítico Superior ha promovido investigaciones que tratan de resolver el problema de su significado a través de la experimentación y de la traceología. Se deben recordar las recientes de Le Brun-Ricalens (1989), Lucas y Hays (2004), Le Brun-Ricalens (2006), Gibaja et al. (2007) etc., así como los estudios funcionales específicos que incluían este tipo de piezas dentro de una amplia muestra de utillaje analizado: Vaughan (1985), Cattin (2002) (1), entre otros. Prácticamente todos ellos se han centrado en las huellas de uso o micropulidos producidos por su supuesto uso, y todos coinciden en interpretarlas como piezas intermedias para el trabajo de materias primas duras. No obstante, la propia dinámica de su utilización, bien como piezas intermedias, bien como núcleos bipolares supone que constantemente las huellas o trazas creadas se destruyan también rápidamente, puesto que interviene siempre una violenta percusión en la que 'saltan' y se pierden los micropuli-

(1) Véase el trabajo doctoral inédito de M. Araújo (2005), Etude fonctionelle de l'industrie lithique d'un grand habitat gravettien en France: les unites op.10 et K119 de la Vigne Brun (Loire). Université Aix-Marseille I. Aix-en-Provence. dos recién creados. Por esta razón en este trabajo optamos por una propuesta experimental que pusiera el énfasis en los caracteres o estigmas macroscópicos para su comprensión y definición, ya que éstos sí permanecen. Esta propuesta pretende ser similar a otras experimentaciones que han abordado útiles cuyas huellas de uso plantean problemas similares, como las puntas de proyectil (Fischer et al. 1984) o las pièces mâchurées (Fagnart y Plisson 1994).

\section{JUSTIFICACIÓN Y OBJETIVOS DE LA PROPUESTA EXPERIMENTAL}

La presente experimentación se planteó con motivo de la problemática de mi tesis doctoral, centrada en la definición del tecnocomplejo gravetiense en la Península Ibérica a través del análisis tecnológico de diferentes conjuntos líticos. La abundancia de las piezas astilladas en sílex en los niveles de Paleolítico Superior inicial del Abrigo de El Palomar (V, IV y III) (Yeste, Albacete), motivó el desarrollo de esta propuesta experimental, centrándose, además, en dicha materia prima (2).

Como paso previo a la enumeración de los objetivos, se debe aclarar que aunque, en teoría, la distinción entre pieza astillada (útil) y núcleo bipolar parece clara (Hayden 1980), los estudios en Prehistoria suelen utilizar en realidad la categoría tipológica de "pieza astillada" indistintamente para ambas variantes o situaciones (Fig. 2). En definitiva, hay un mismo significante para dos significados muy distintos. La propuesta experimental subsiguiente trata de aclarar qué morfologías y estigmas se obtienen macroscópicamente para estos dos tipos de actividades que se han relacionado con el morfotipo de "pieza astillada". Como objetivos específicos se plantean: determinar si ambas actividades generan lo que en tipología se clasifica como "piezas astilladas" o "retoque astillado" y especificar si es posible distinguir de visu las piezas talladas por percusión bipolar y las utilizadas como útiles intermedios. Además, se describirán en detalle los desconchados/extracciones macroscópicos producidos durante la experimentación.

(2) P. de la Peña, "Propuesta experimental sobre piezas astilladas: el ejemplo de la talla bipolar". Poster presentado en las II Jornadas de Jóvenes en Investigación Arqueológica (Universidad Complutense, Madrid, 6 a 8 de mayo 2009). 


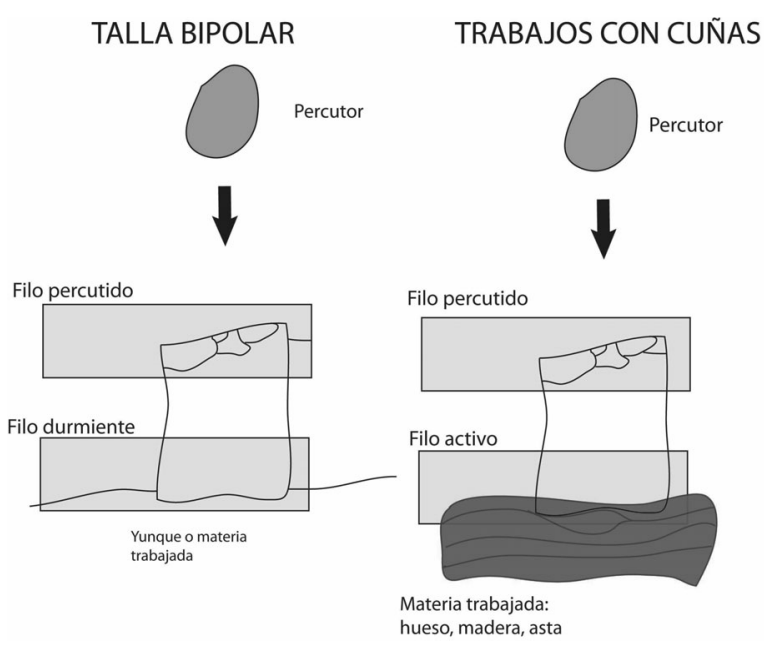

Fig. 2. Esquema con los dos tipos de experimentaciones desarrolladas y denominación de los fílos en el marco de este estudio.

\section{PRESENTACIÓN ESQUEMÁTICA DE LA EXPERIMENTACIÓN Y METODOLOGÍA DE ESTUDIO}

La experimentación se concibió como "mixta" (González Urquijo e Ibáñez 1994). A partir de variables conocidas y controladas, pero de manera replicativa, con el objetivo de intentar reproducir los trabajos llevados a cabo en el pasado.

\subsection{Experimentación 1: talla bipolar}

La experimentación consistió en la talla por percusión directa de cantos, lascas y otros restos de talla resultantes, apoyándolos sobre un yunque para producir soportes líticos (Figs. 3 y 4). Para la percusión del sílex (3) se emplearon percutores minerales y orgánicos, con el objetivo de observar posibles diferencias entre este tipo de percusiones. Las principales variables que intervinieron en esta experimentación fueron: la actividad/ forma de aplicación de la fuerza: percusión directa; la morfología de la zona activa (percutor): redondeada (al tratarse de un canto, de asta o madera de boj) y de la zona percutida: redondeada (canto), lisa (talón o fragmento de lasca no reto-

(3) La variedad de sílex seleccionada para todos los trabajos experimentales presentados fue de tipo Bergerac (Francia), cuyas características eran muy similares al sílex bético documentado en los niveles de Paleolítico Superior inicial del Abrigo de El Palomar, de grano fino y excelente calidad.

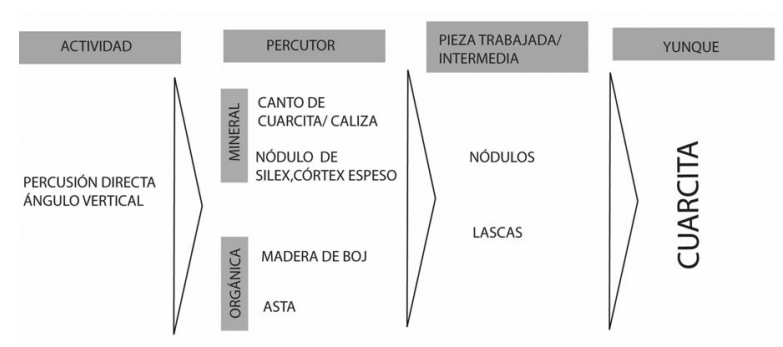

Fig. 3. Hipótesis 1: esquema de la experimentación con talla bipolar.

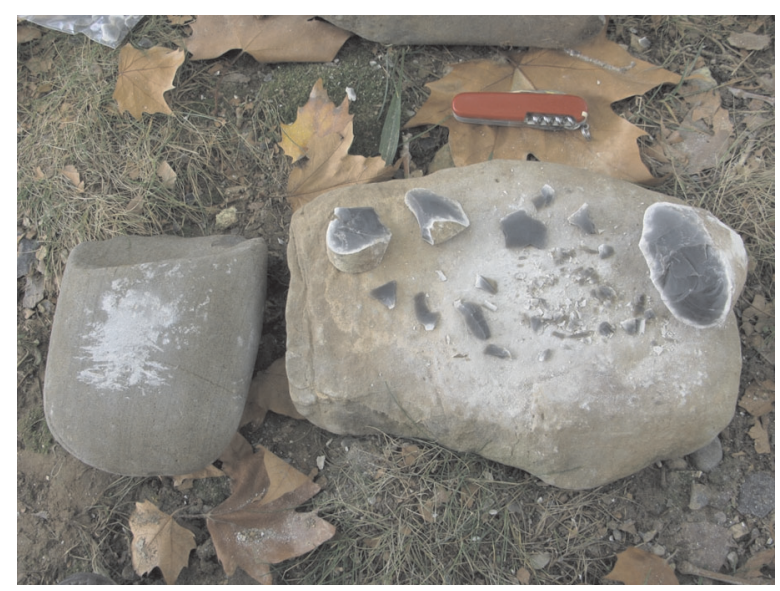

Fig. 4. Canto de sílex tallado por el método bipolar durante la experimentación (fotografía Paloma de la Peña).

cada-retocada) o aguda (filo de lasca); el ángulo de trabajo: trayectoria seguida por la proyección de las articulaciones de la extremidad superior, marcando una curva e intentando la percusión vertical $\left(90^{\circ}\right)$. Además, se consideraron el número límite de acciones para extraer soportes o sujetar el núcleo; la forma de sujeción: con la mano desnuda y el ángulo del filo del material tallado: liso (si se tallaba un canto rodado), filo menor a $90^{\circ}$ (si se trataba de una lasca).

\subsection{Experimentación 2: útiles intermedios para trabajos de cuña}

La experimentación utilizó lascas y restos de talla de distintas morfologías como soportes intermedios para cortar o abrir, a modo de cuña vertical, materias primas duras (hueso, madera y asta) (4).

(4) La selección de especies animales y madereras se realizó para cubrir diferentes morfologías y grados de dureza. 
Las dos primeras se trabajaron por corte, segmentación o bipartición (abrir en dos), mientras el asta sólo por corte o segmentación.

Dentro del trabajo con hueso se realizaron cortes transversales sobre huesos largos (10 tests) y epífisis de costillas de Bos taurus (10 tests) y longitudinales sobre los extremos laterales de las mismas (6 tests). Por bipartición se abrieron varios metápodos de Sus scrofa domestica (7 tests), costillas de Bos taurus y Rangifer tarandus (17 tests). Es decir, se plantearon acciones que requiriesen respectivamente fuerza (huesos largos) y precisión (bipartición de metápodos o costillas) aplicadas sobre huesos de carácter duro y competente y de características esponjosas y 'amortiguadoras'. En las figuras 5 y 6 se resumen todos los trabajos llevados a cabo con hueso.

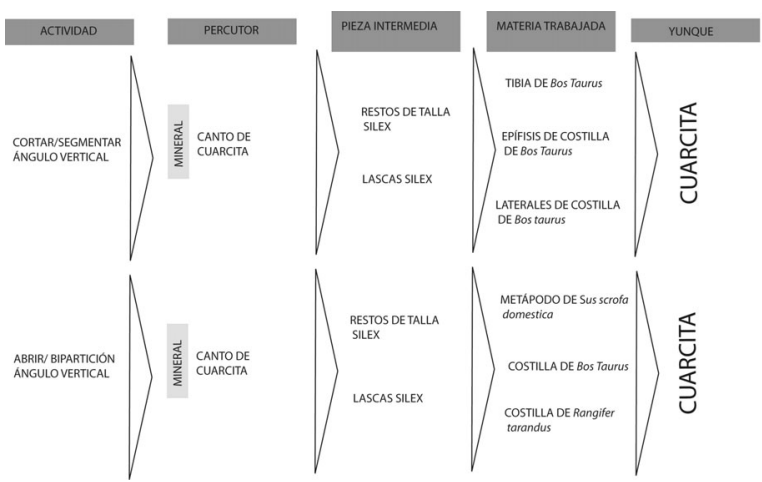

Fig. 5. Esquema de la experimentación desarrollada con huesos de diferentes especies.

\section{TRABAJOS DE CUÑA CON HUESO}

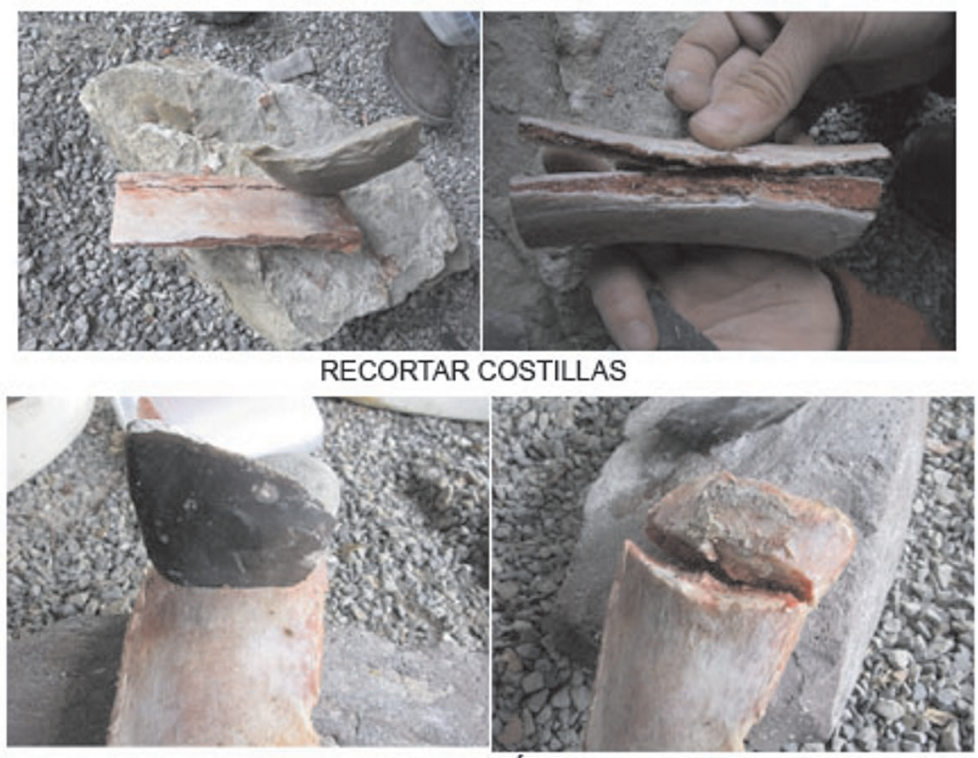

CORTAR EPIFISIS

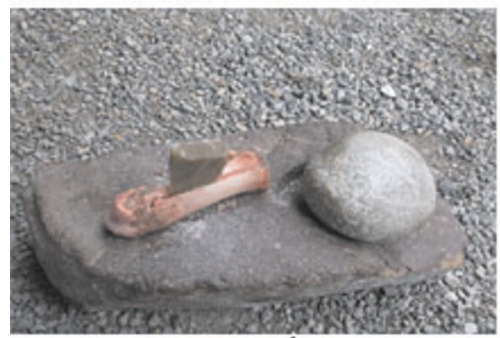

ABRIR METÁPODO
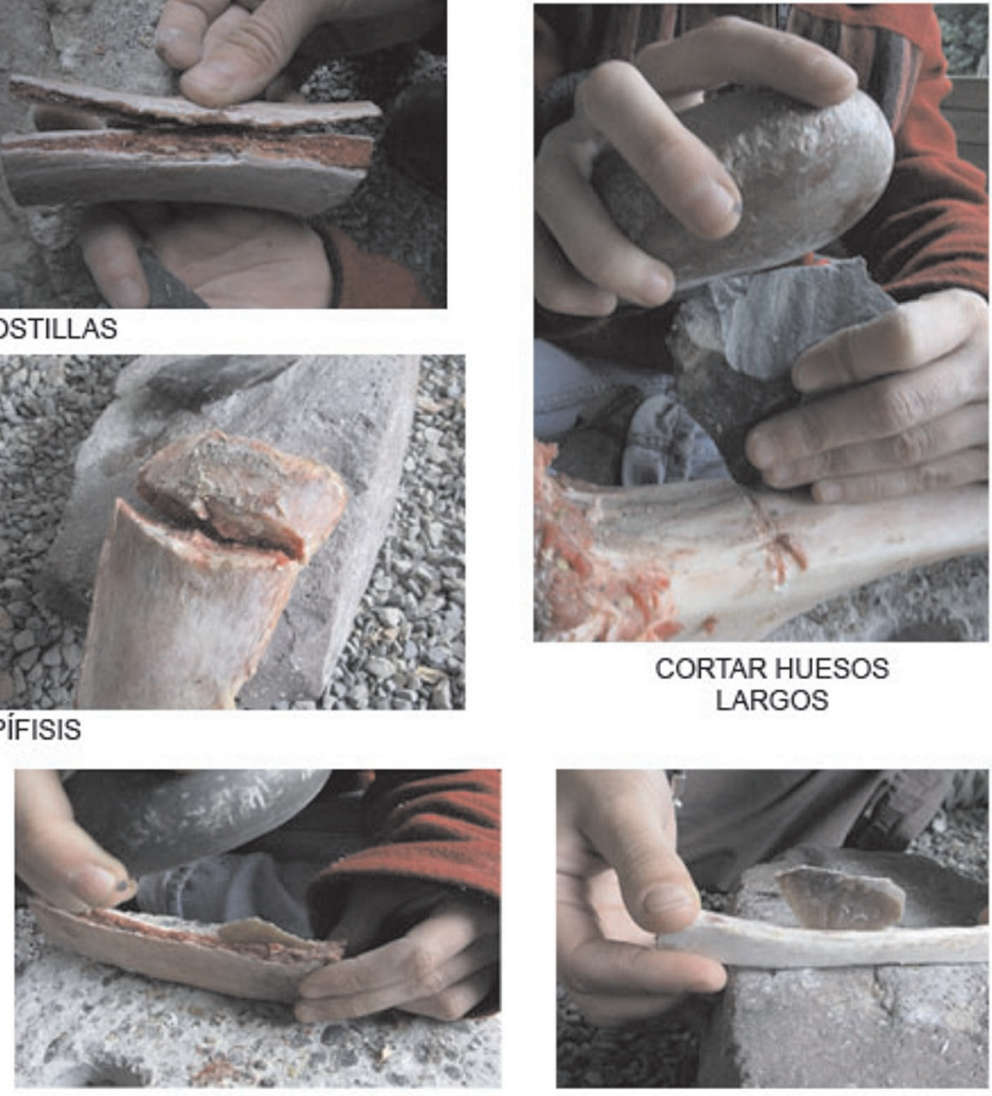

CORTAR HUESOS

LARGOS

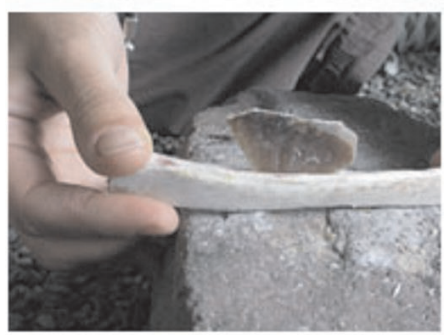

ABRIR COSTILLAS

Fig. 6. Trabajos durante la experimentación en hueso. Recorte lateral de costillas; segmentación o corte transversal de costillas; bipartición de metápodos y costillas; detalle de la experimentación de segmentación o corte de huesos largos (fotografías Paloma de la Peña). 
La madera trabajada eran ramas de entre 3-5 $\mathrm{cm}$ de diámetro y segmentos de troncos de entre 15-20 cm de diámetro. Las primeras eran de $A c a-$ cia triacanthos, Quercus robur, Salix repens y Populus alba, para evaluar diferentes durezas. Se realizaron tanto acciones de corte transversal (34 tests) como de bipartición longitudinal (15 tests). Los troncos eran de Fagus sylvatica, Carpinus betulus y Buxus sempervirens y sólo se trabajaron por bipartición (29 tests). En la figura 7 se resumen las actividades con madera.

En la experimentación con asta se seccionaron varios fragmentos de Rangifer tarandus (23 tests) (detalle en Fig. 7).

A continuación se describen las variables independientes, es decir los factores "que influyen de manera significativa en las huellas resultantes del trabajo" (González Urquijo e Ibáñez 1994: 19), con respecto a esta variante experimental. La actividad/forma de aplicación de la fuerza fue la percusión indirecta y la morfología del filo de la zona percutida: lascas y restos de talla de todo tipo, con filos agudos o romos. La morfología de la pieza intermedia fue, a su vez, lascas y restos de talla de todo tipo pero con terminaciones preferiblemente agudas. Como ángulo de trabajo se tomó la trayectoria seguida por la proyección de las articulaciones de la extremidad superior, marcando una curva intentándose aproximar a la percusión vertical. También se consideraron el número de acciones o golpes mientras la pieza 'trabajaba', la forma de sujeción a mano desnuda y el ángulo del filo activo entre la zona activa y el apoyo sobre la materia trabajada (siempre menor a $\operatorname{los} 90^{\circ}$ ).

Las trazas macroscópicas se describieron siguiendo a González e Ibáñez (1994), con algunas adaptaciones: delineación del filo, densidad de las extracciones, posición, distribución, disposición, extensión y tamaño (grande superior a $5 \mathrm{~mm}$, medio entre $1-5 \mathrm{~mm}$ y pequeño inferior a $1 \mathrm{~mm})$.

En la descripción de los resultados experimentales, se diferenciará entre la denominación de las extracciones producidas por la talla bipolar y por el trabajo de cuña. En el caso de la talla bipolar se ha empleado el término "extracción" ya que son fruto de una percusión voluntaria. Sin embargo, en la otra hipótesis las extracciones se han denominado "desconchados" ya que se producen por el tipo de trabajo realizado y su generación no constituye un acto voluntario. En cuanto a la
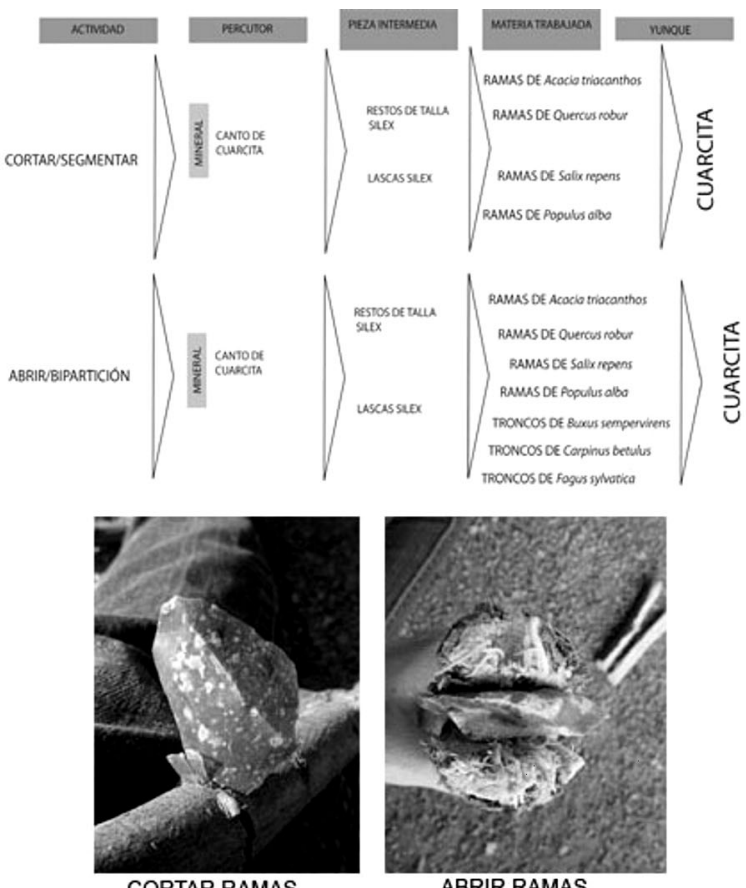

CORTAR RAMAS

ABRIR RAMAS
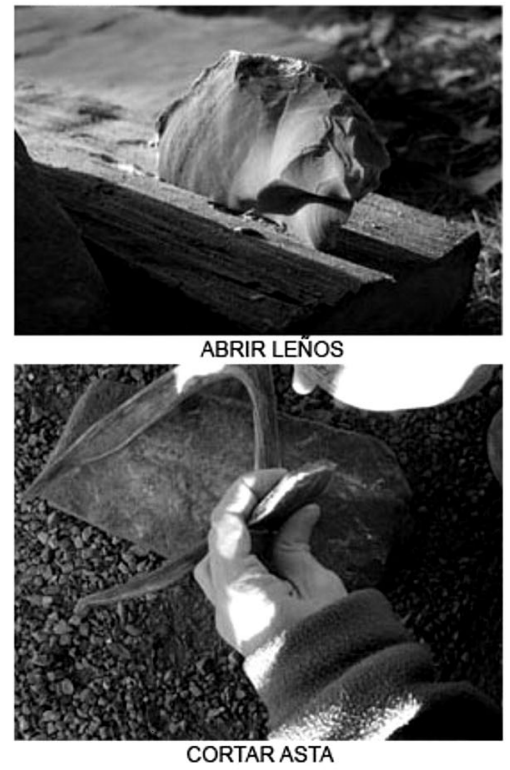

Fig. 7. Arriba, esquema de la experimentación sobre madera. Abajo, diferentes trabajos desarrollados con piezas de sílex sobre madera y asta (fotografías Paloma de la Peña).

terminología de los filos, se ha denominado en las dos hipótesis al borde directamente percutido como "filo percutido", mientras que el opuesto (apoyado sobre el yunque) en la percusión bipolar se ha llamado "filo posado" y en la otra hi- 
pótesis como "filo activo", al haber trabajado directamente sobre la materia (hueso, madera o asta) (Fig. 2).

\section{RESULTADOS DE LA TALLA BIPOLAR O TALLA POSADA SOBRE YUNQUE}

La experimentación permitió comprobar que se producen abundantes soportes (astillas) y restos de talla fruto de la percusión directa tanto en el filo percutido como por contragolpe, es decir, provenientes del filo apoyado sobre el yunque. Las principales características macroscópicas de los núcleos tallados mediante el método bipolar se presentaron ya en un trabajo preliminar sobre las piezas astilladas del Nivel V del Abrigo de El Palomar, atribuido al Paleolítico Superior inicial (5), así como en otras propuestas experimentales sobre períodos posteriores ( $\mathrm{Gu}$ yodo y Marchand 2005; Donnart et al. 2009). Completan el panorama las publicaciones de Díez- Martín et al. (2009) y Mourre (1996, 2004) centradas en diferentes tipos de cuarzo y cuarcita del Paleolítico Inferior y Medio, respectivamente.

Los principales estigmas consignados en nuestra experimentación -que permiten su comparación con los trabajos a modo de cuña- son que el filo percutido y el posado se regularizan, tienden a hacerse rectilíneos. Si la zona percutida se va rotando sobre sí misma, se obtienen morfologías cuadrangulares y rectangulares (Fig. 8A). Se generan numerosas extracciones, tanto en la zona percutida como en la zona apoyada sobre el yunque si bien, normalmente, son mayoritarias las del borde percutido. Las extracciones son bifaciales si el ángulo del filo es simétrico (Fig. 8B), pero si la pieza es asimétrica tienden al reequilibrio -desarrollándose únicamente en una cara- (Fig. 10A). Por ejemplo, si el perfil de la pieza es convexo-recto las extracciones tenderán hacia el lado convexo, reequilibrando el ángulo. El filo percutido sufre un notable 'retroceso' por motivo de la fuerte percusión lo que explica la reducción de tamaño de los núcleos residuales (Figs. 8F y 10B). Se pro-

(5) Véase nota 2. duce una eventual preparación 'involuntaria' del plano de fractura. Es decir, a medida que la percusión regulariza el borde percutido se genera poco a poco una superficie recta y lineal que en un determinado momento permite la extracción de soportes de tipo hojita-lasquita (Figs. 8I y 10C). Las terminaciones de las extracciones obtenidas por la percusión suelen ser en escalón o reflejadas (Fig. 8G). Así como los negativos de las extracciones en los núcleos bipolares presentan normalmente ondas de percusión muy marcadas (Fig. 8H). Las extracciones, sobre todo en el filo percutido, tienden primero a formar grandes extracciones que se suelen superponer y reflejar entre sí. Las extracciones reflejadas previas obligan a que las siguientes sean más pequeñas $\mathrm{y}$, de nuevo, se reflejan, generándose normalmente una segunda fila de extracciones subalineadas. Por último, la zona inmediata al filo se va fisurando, resquebrajando y rompiendo (Figs. 8C y 10D). La fuerte percusión produce una especie de pulido en el filo, mientras que la zona inmediatamente próxima queda completamente fisurada (Fig. 8D y E).

Las características de los soportes buscados, las astillas, se describen a continuación. Generalmente poseen talones rotos o lineales, ya que corresponden a un fragmento del filo violentamente percutido. Por esta misma razón, también portan la parte inmediata al filo que hemos descrito como "fisurada" (Fig. 9A). Los restos de talla no presentan un punto de impacto distinguible. Las ondas de percusión en las caras bulbares son muy marcadas y están muy próximas entre sí (Fig. 9D). El perfil de los soportes es de tendencia rectilínea. No obstante, esto también depende de la morfología del núcleo (Fig. 9D). Se ha observado un accidente de talla recurrente: la generación de un bulbo muy marcado y abultado "reflejado" (Fig. 9B).

En los percutores y yunques (en cuarcita y caliza) se desarrollan trazas o estigmas lineales y, ocasionalmente de piqueteado, muy marcadas y concentradas (Fig. 9C y F). También aparecen cúpulas o cazoletas (Fig. 9E), producto de la fuerte percusión, como ya apuntó Le Brun-Ricalens (1989). El empleo de percutores de asta y madera de boj resultó altamente ineficaz por la menor masa de dichas materias primas y por 'dañarse' rápidamente su superficie, fruto de la violenta percusión necesaria para este tipo de método de talla. 

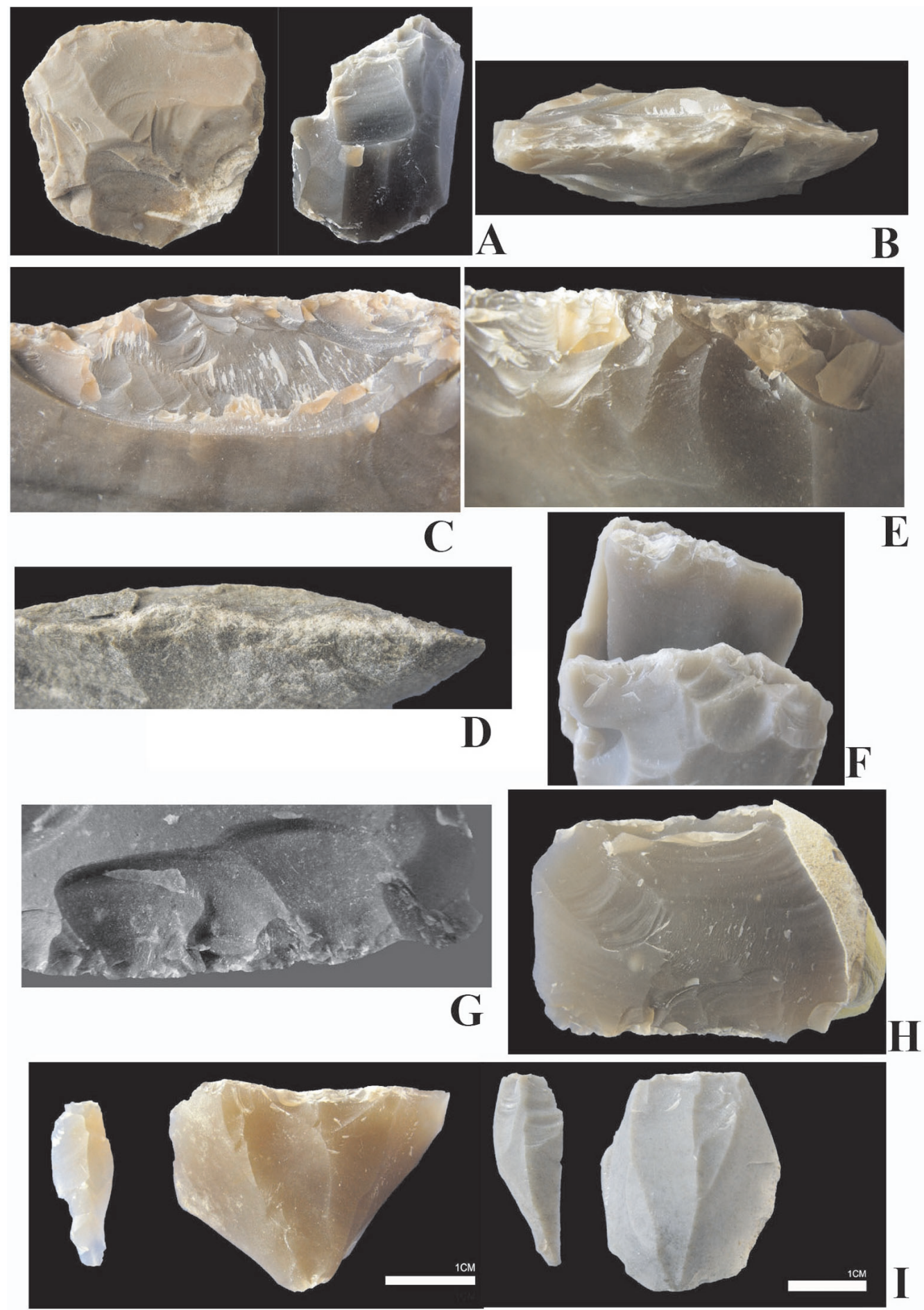

Fig. 8. Características macroscópicas de núcleos de sílex tallados por percusión posada sobre yunque (talla bipolar): A. Morfologías residuales rectilíneas de los núcleos bipolares, obsérvese que poseen características idénticas a la de las piezas astilladas. B. Desarrollo bifacial de las extracciones por la simetría del perfil de la pieza. C. Superposición de las extracciones. D. Embotamiento del filo. E. Detalle de fisuración del filo. F. Retroceso del filo percutido (remontaje experimental). G. Terminación abrupta de las extracciones: reflejadas y en escalón. H. Desarrollo marcado de las ondas de percusión en un núcleo bipolar experimental. I. Ejemplos de astillas y núcleos bipolares (fotografías Paloma de la Peña). 


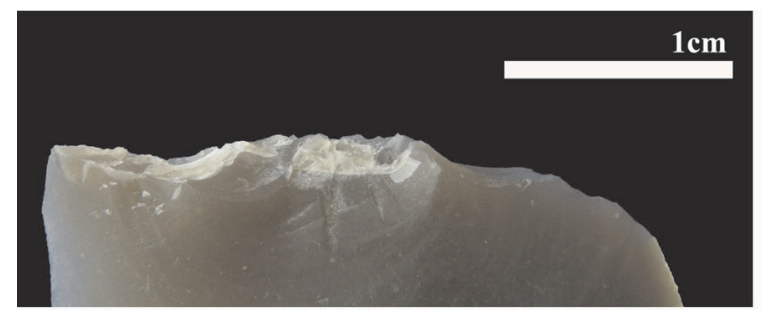

A
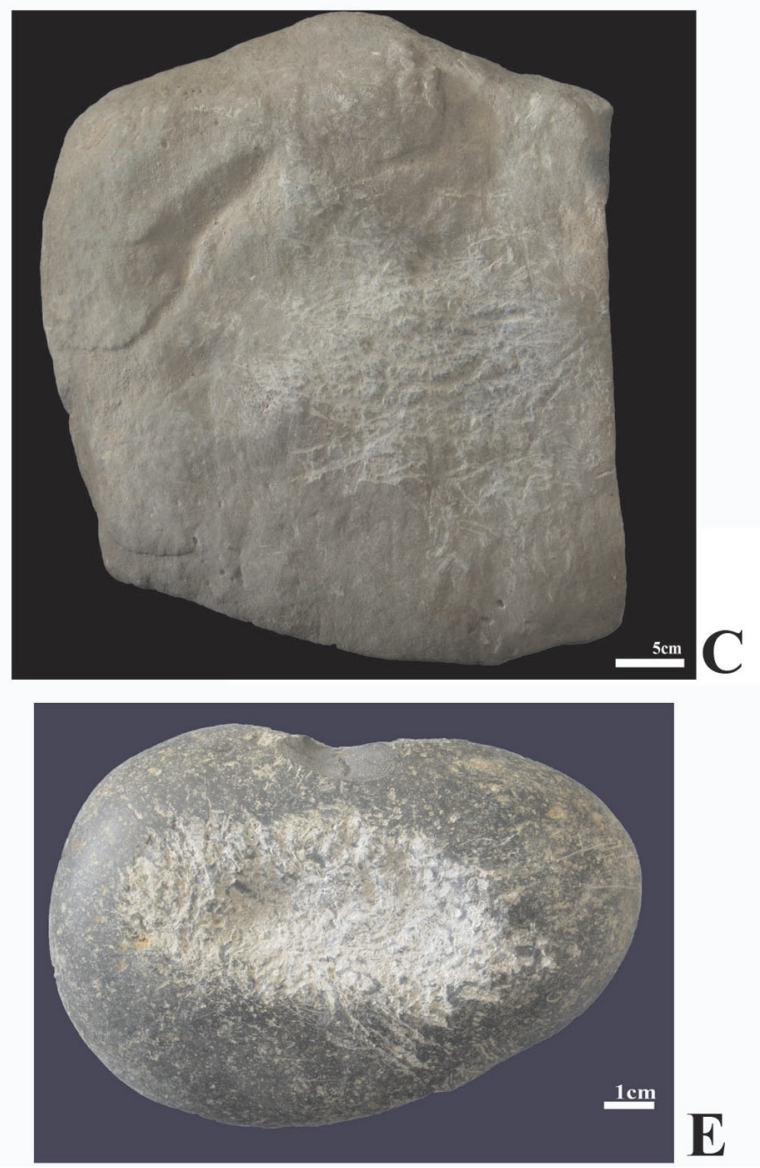

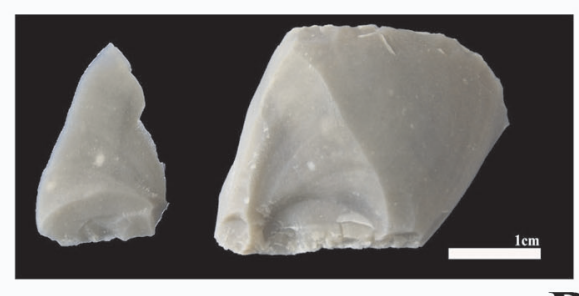

B

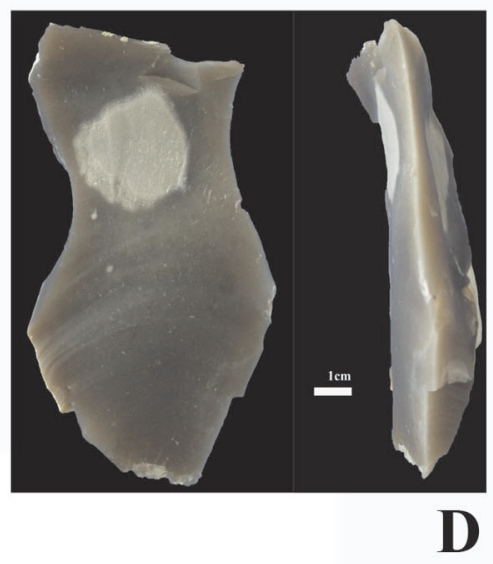

D

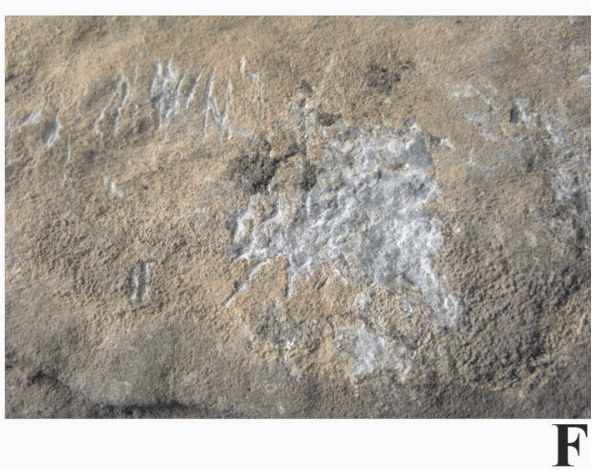

Fig. 9. Características macroscópicas de astillas, percutores y yunques implicados en la talla bipolar: A. Talón roto y fisurado de astilla; B. Astilla con reflejo accidental del bulbo y núcleo bipolar del que proviene; C. Yunque en cuarcita con trazas lineales concentradas y desarrollo de cúpulas; D. Reverso de astilla y perfil rectilíneo del mismo soporte; E. Percutor en caliza con desarrollo de cúpula; F. Estigmas lineales y de piqueteado en yunque de cuarcita (fotografías Paloma de la Peña). 


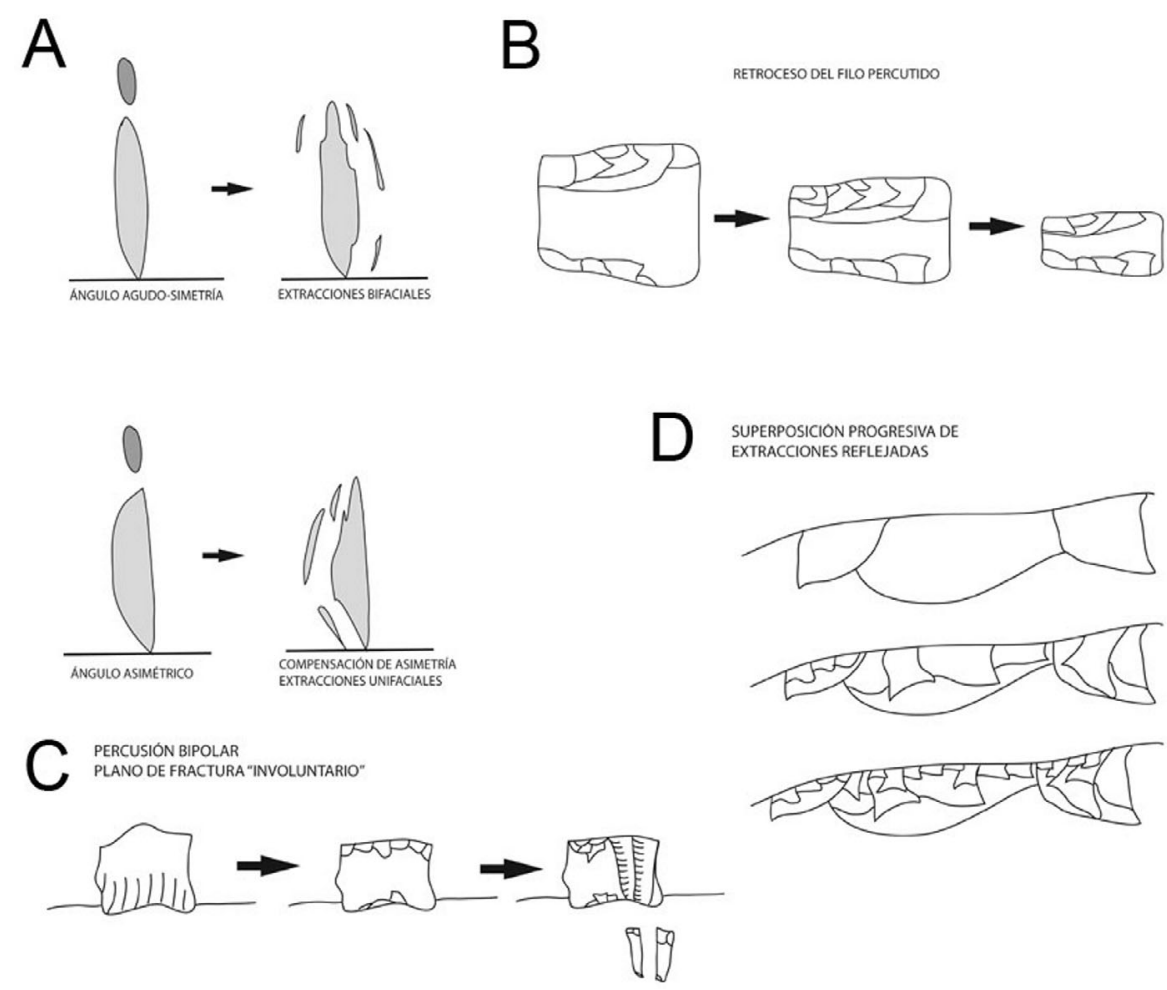

Fig. 10. Diferentes características consignadas durante la experimentación con talla bipolar: A. Desarrollo asimétrico de las extracciones en función de la morfología de la pieza; B. Disminución progresiva del tamaño de los núcleos; C. Desarrollo involuntario de plano de fractura lineal; D. Disminución creciente de tamaño de las extracciones, fruto de los sucesivos reflejados.

\section{RESULTADOS DEL EMPLEO DE PIEZAS INTERMEDIAS PARA EL TRABAJO DE HUESO, MADERA Y ASTA EN ACTIVIDADES DE TIPO CUÑA}

En los trabajos de tipo cuña, el resultado cualitativo de las extracciones en el filo directamente percutido de las piezas intermedias es prácticamente idéntico al descrito para la talla bipolar (fisuración, embotamiento, retroceso del filo, etc.) Ello se debe a que se aplica un mismo tipo de percutor y que el filo apoyado sobre la materia trabajada ofrece una resistencia similar. Nos encontramos por tanto ante una situación de equifinalidad, es decir, unos estigmas macroscópicos idénticos para el filo percutido en las dos actividades planteadas. Sin embargo, se debe apuntar que se observó cómo el desarrollo y extensión de las extracciones en dicho filo es directamente proporcional a la fuerza aplicada en cada caso: los trabajos que requirieron más fuerza mostraban acusadas extracciones, mientras que en los de precisión su desarrollo era moderado (Tab. 1).

En el filo activo (filo apoyado sobre la materia trabajada), sí se observaron diferencias cualitativas con respecto a los estigmas resultantes de la talla posada sobre yunque. A continuación son descritos pormenorizadamente por ser los más ilustrativos y discriminantes en el marco de esta experimentación:

\subsection{Actividades de cuña con huesos}

Las variantes de los trabajos con hueso que requirieron más aplicación de fuerza fueron el corte de huesos largos y de epífisis de costilla de bóvido. Provocaron numerosos desconchados de tamaño medio y grande (superiores a $5 \mathrm{~mm}$ ), en el filo percutido y en el activo. Las características 


\begin{tabular}{|c|c|c|c|c|c|}
\hline \multirow{2}{*}{\multicolumn{2}{|c|}{$\begin{array}{l}\text { VARIANTES DE LA } \\
\text { EXPERIMENTACIÓN }\end{array}$}} & \multicolumn{2}{|c|}{$\begin{array}{c}\text { Filo } \\
\text { percutido }\end{array}$} & \multicolumn{2}{|c|}{$\begin{array}{c}\text { Filo } \\
\text { durmiente/activo }\end{array}$} \\
\hline & & $T$ & E & $T$ & E \\
\hline \multicolumn{2}{|c|}{ Hipótesis 1. Talla bipolar (sílex) } & G & I & G & $\mathrm{I} / \mathrm{M}$ \\
\hline \multirow{13}{*}{$\begin{array}{l}\text { Hipótesis } 2 \\
\text { Trabajos de } \\
\text { cuña }\end{array}$} & Hueso & & & & \\
\hline & $\begin{array}{l}\text { Cortar huesos largos (Bos } \\
\text { taurus) }\end{array}$ & G & I & $\mathrm{G} / \mathrm{M}$ & $\begin{array}{l}\text { a veces } \\
\mathrm{I} / \mathrm{M}\end{array}$ \\
\hline & $\begin{array}{c}\text { Cortar costilla (Bos tau } \\
\text { rus })\end{array}$ & G & I & $\mathrm{M} / \mathrm{P}$ & $\mathrm{M} / \mathrm{Mr}$ \\
\hline & $\begin{array}{l}\text { Cortar lateral de costilla } \\
\quad \text { (Bos taurus) }\end{array}$ & G & M & $\mathrm{M} / \mathrm{P}$ & $\mathrm{M} / \mathrm{Mr}$ \\
\hline & $\begin{array}{c}\text { Abrir metápodos (Sus } \\
\text { scrofa domestica) }\end{array}$ & $\mathrm{G} / \mathrm{M}$ & M & $\mathrm{M} / \mathrm{P}$ & $\mathrm{M} / \mathrm{Mr}$ \\
\hline & $\begin{array}{l}\text { Abrir costillas (Bos tau } \\
\text { rus) }\end{array}$ & $\mathrm{G} / \mathrm{M}$ & $\mathrm{M} / \mathrm{I}$ & $\mathrm{M} / \mathrm{P}$ & $\mathrm{M} / \mathrm{Mr}$ \\
\hline & $\begin{array}{l}\text { Abrir costillas (Rangifer } \\
\text { tarandus) }\end{array}$ & $\mathrm{M}$ & M & $P$ & $\mathrm{Mr}$ \\
\hline & Madera & & & & \\
\hline & $\begin{array}{l}\text { Cortar ramas (Acacia tria- } \\
\text { canthos, Quercus ro- } \\
\text { bur, Salix repens y Po- } \\
\text { pulus alba) }\end{array}$ & G & I & $\mathrm{M} / \mathrm{P}$ & $\mathrm{M} / \mathrm{Mr}$ \\
\hline & $\begin{array}{l}\text { Abrir ramas (Acacia tria- } \\
\text { canthos, Quercus ro- } \\
\text { bur, Salix repens y Po- } \\
\text { pulus alba) }\end{array}$ & M & M & $\mathrm{P}$ & $\mathrm{Mr}$ \\
\hline & $\begin{array}{l}\text { Abrir tronco (Buxus sem- } \\
\text { pervirens) }\end{array}$ & G & I & $\begin{array}{c}\mathrm{M} / \mathrm{a} \\
\text { veces } \mathrm{G}\end{array}$ & $\begin{array}{c}\mathrm{M} / \mathrm{a} \\
\text { veces I }\end{array}$ \\
\hline & $\begin{array}{l}\text { Abrir troncos (Fagus syl- } \\
\text { vatica y Carpinus betu- } \\
\text { lus) }\end{array}$ & G & I & $\mathrm{M} / \mathrm{P}$ & $\mathrm{M} / \mathrm{Mr}$ \\
\hline & Asta (Rangifer tarandus) & G & I & $\mathrm{G} / \mathrm{M}$ & $\begin{array}{l}\text { a veces } \\
\mathrm{I} / \mathrm{M}\end{array}$ \\
\hline
\end{tabular}

Tab. 1. Tamaño de las extracciones y desconchados en los diferentes trabajos desarrollados (T: Tamaño; E: Extensión; G: grande; M: medio; P: pequeño; I: invasor; Mr: marginal). Obsérvese la correlación entre materiales duros, mayor tamaño y extensión de las extracciones (casillas marcadas en gris claro). Por el contrario, las tareas que dosificaban la fuerza y se realizaban sobre materiales más 'absorbentes' producen extracciones y extensiones menos desarrolladas.

del filo activo difirieron de los resultantes de los otros trabajos en hueso y de los descritos para la talla bipolar. Se resumen en: la irregularidad de la delineación del filo, fruto de fracturas y desconchados de gran tamaño (Fig. 11B y D); la heterometría de los desconchados, distribuidos en tamaños irregulares a lo largo del filo (Fig. 11D y E) y en la adquisición de la morfología del hueso trabajado (curvatura) (Fig. 11C y E).

Estos dos trabajos se realizaron con lascas o restos de talla de tamaño superior a los $6 \mathrm{~cm}$ de longitud. Las lascas inferiores resultaban altamente ineficaces al romperse tanto por la percusión violenta como por el contragolpe recibido del hueso percutido. Por otra parte, una buena selección de la morfología de los soportes o útiles de trabajo -sobre todo para seccionar las epífisisfacilitaba mucho esta tarea. También se requerían piezas de espesor superior a los 2-3 cm.

Las morfologías resultantes de las piezas intermedias utilizadas en la experimentación corresponden tipológicamente a las de las piezas astilladas, por poseer dos filos opuestos con extracciones muy marcadas y un pseudo retoque $a$ posteriori de astillamiento. No obstante, difieren de las características observadas en la talla bipolar por la irregularidad de la delineación del filo activo, la aparición de fracturas y por el desarrollo diferente de los desconchados y de su ordenación (heterometría).

El resto de trabajos con hueso (el corte de extremos laterales de costilla de bóvido, la apertura de metápodos y la bipartición de costillas) generaron desconchados en el filo activo, pero en menor densidad, extensión y tamaño (generalmente medianos y pequeños) (Tab. 1). Incluso, se llegó a observar que apenas se producían desconchados visibles. En otros términos, estas acciones en el filo activo no produjeron lo que tipológicamente se denomina retoque astillado, sino ciertas fracturas o desconchados. Esto se debe a que todas estas actividades eran de mayor precisión y requerían una dosificación de la fuerza para su correcta consecución. Resumiendo, los estigmas identificados son: menor extensión de las extracciones en el filo percutido que lo advertido en los dos trabajos en hueso anteriores (Fig. 12B1). Prácticamente la totalidad de los desconchados desarrollados en el filo activo fueron de tamaño pequeño, a lo sumo mediano (Fig. 12A1 y C1; Fig. 13A2 y B2; Fig. 14A, B y C2). Las extracciones en el filo activo están mucho menos desarrolladas que el filo percutido, es decir, existe una 'asimetría' en tamaño y en extensión entre los dos filos (Fig. 13A1/A2 y B1/B2; Fig. 14A, B y C). Las extracciones desarrolladas en el filo activo tienen una morfología de pseudorretoque o desconchado no identificable con lo definido normalmente como retoque astillado (Fig. 12A1 y C1; Fig. 13A2 y B2; Fig. 14C2). 

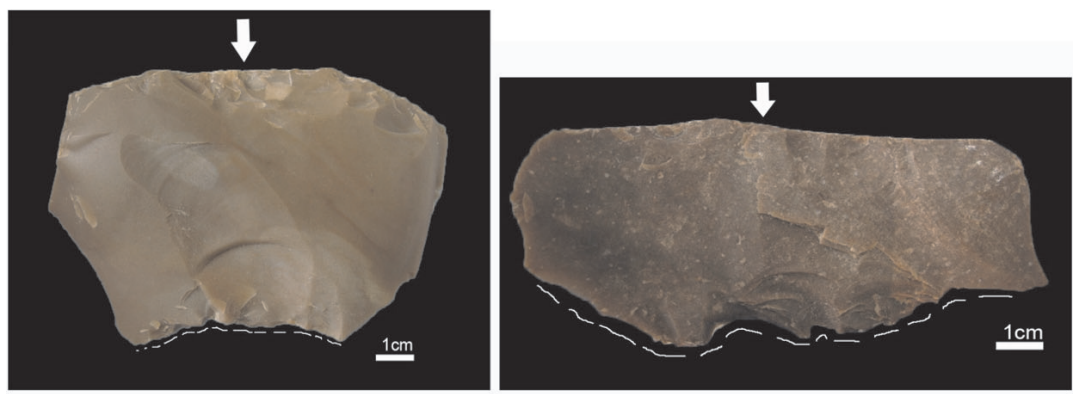

A

B
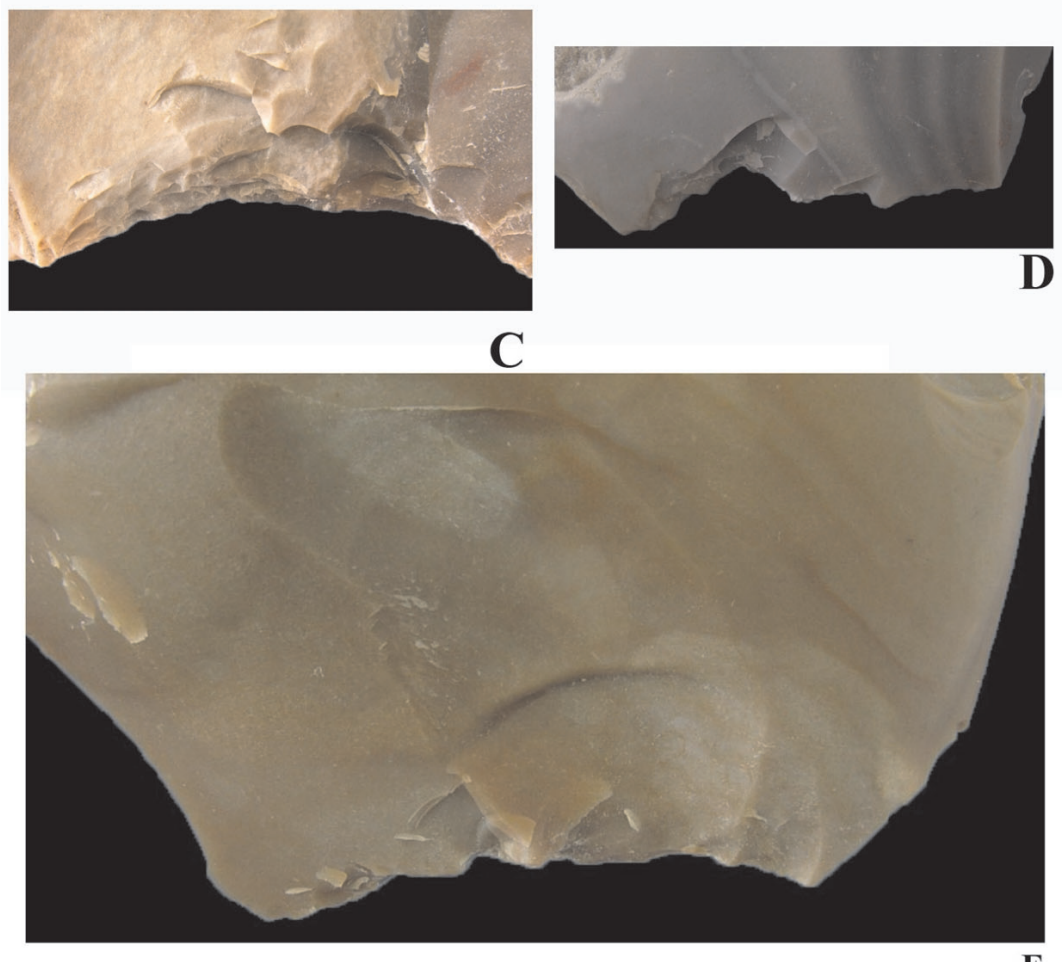

Fig. 11. Actividades de cuña para el corte de huesos largos (tibia) y de epífisis de costillas de bóvido: morfologías obtenidas y detalle de desconchados. Las flechas señalan el filo percutido y el trazo discontinuo de las partes de las piezas apoyadas sobre la materia trabajada (sirva esta aclaración para todas las fotografías que se presentan más abajo con estos signos). Obsérvese el carácter rectilíneo del filo percutido (regularizado), contrastando con el activo (delineación irregular) y la heterometría de los desconchados generados en este último (E y D). Arriba dos ejemplos (A y B) de piezas enteras, abajo (C, D y E) detalles de los filos activos (fotografías Paloma de la Peña).

\subsection{Actividades de cuña con madera}

La experimentación con madera se inició cortando transversalmente pequeñas ramas de 5-10 $\mathrm{cm}$ de diámetro. Las extracciones resultantes en las diferentes especies se exponen en conjunto puesto que, pese a que la dureza de algunas variantes como la acacia era mayor, las características generales fueron similares.
Antes de iniciar los trabajos de cuña con madera y asta (vid. infra) se realizó una pequeña incisión en la materia trabajada para 'acomodar' mejor la pieza intermedia. La experiencia con ramas de diferentes especies se efectuó en seco.

La mayor parte de las piezas $(n=20 / 34)$ se fracturaron al tratar de seccionar o cortar las ramas transversalmente. Esto lo atribuimos a que al ejercer una fuerza perpendicular al desarrollo 

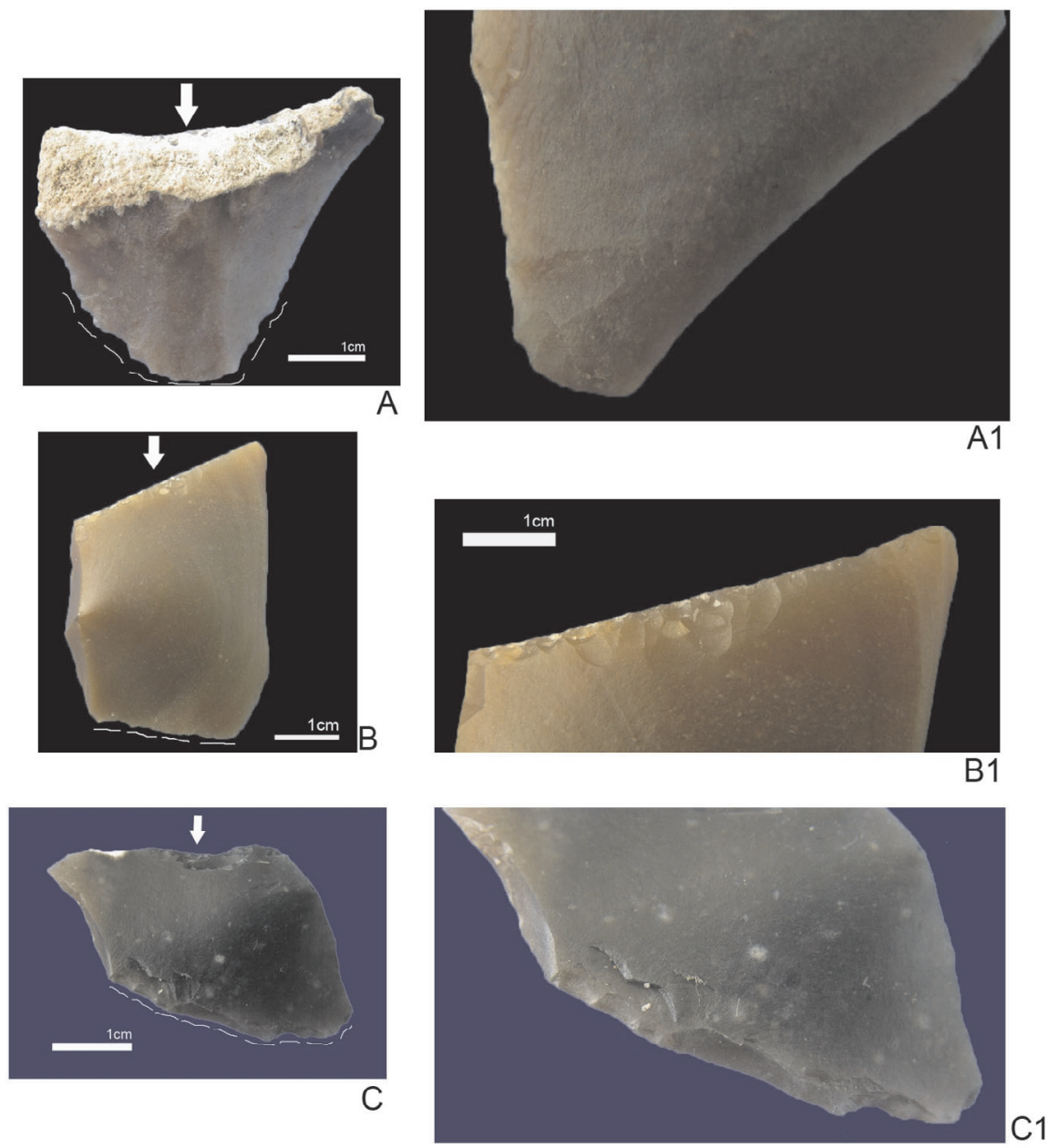

Fig. 12. Piezas experimentales utilizadas para abrir metápodos por bipartición (signos explicados en Fig. 11). Obsérvese el desarrollo limitado de los desconchados en el filo activo (A1 y C1) e, incluso en el percutido (B1) (fotografías Paloma de la Peña).

de las fibras vegetales la materia trabajada ofrece mayor resistencia. Una vez fracturadas, las cuñas perdían su eficacia, al no existir un filo agudo que penetrase en la materia. Las fracturas, en su mayoría, son semicirculares -respondiendo a la forma de las ramas-, además suelen ser casi lisas o de tipo flexión, con una pequeña lengüeta.

Las características fundamentales del filo activo tras el trabajo son: la abundancia de fracturas por flexión (Fig. 15B2), la delineación irregular del filo activo (Fig. 15B2 y B4) y el desarrollo restringido, en extensión y en tamaño, de los desconchados (Fig. 15A1, B4 y C2). En definitiva, en este trabajo tampoco se produjo (en el filo activo) lo que tipológicamente se reconoce como retoque astillado.
La bipartición de ramas se puede considerar como un trabajo de precisión, dado que no requiere mucha fuerza sino destreza, tanto en la colocación de la cuña como en el aprovechamiento de la morfología de las fibras vegetales. Las piezas en esta actividad también se fracturaron con frecuencia, aunque las fracturas poseen un tamaño menor que se restringe al área inmediata al filo. Además, al contrario que en el anterior trabajo, las piezas tras su fracturación siguieron funcionando bien, ya que los flancos laterales de la lasca y no el borde del filo activo ejercieron la fuerza principal. Como esta actividad requirió una fuerza más dosificada, el desarrollo o extensión de los desconchados en el filo percutido y activo fue menor que en el trabajo anterior. Sólo en 3 de las 15 cuñas se observan 

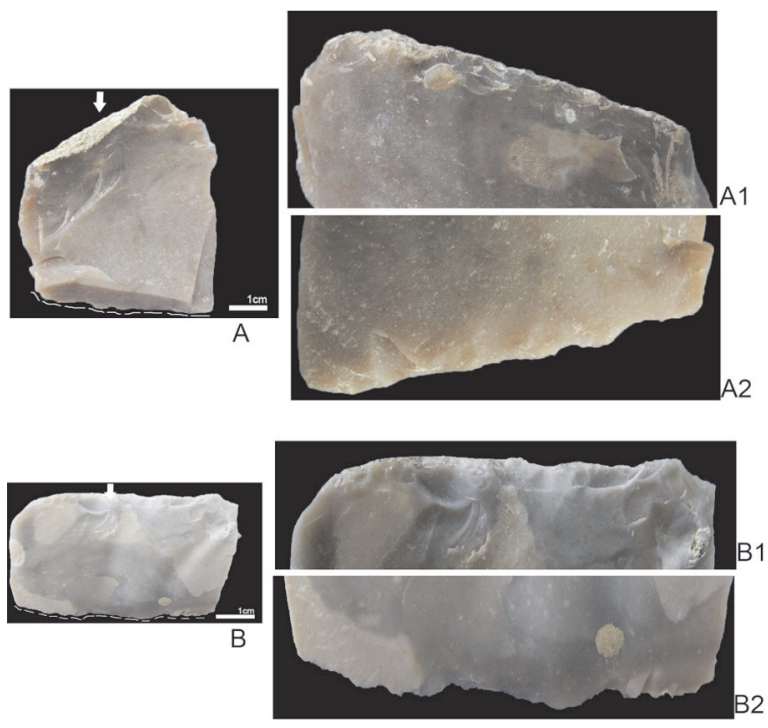

Fig. 13. Piezas experimentales empleadas para cortar epífisis de costilla de bóvido (signos explicados en Fig. 11). Las flechas sobre las que se sitúan los filos percutidos (A1 y B1) y el trazo discontinuo los activos (A2 y B2). Obsérvese el desarrollo limitado e irregular de los desconchados en los filos activos, no asimilable al retoque astillado (fotografías Paloma de la Peña).
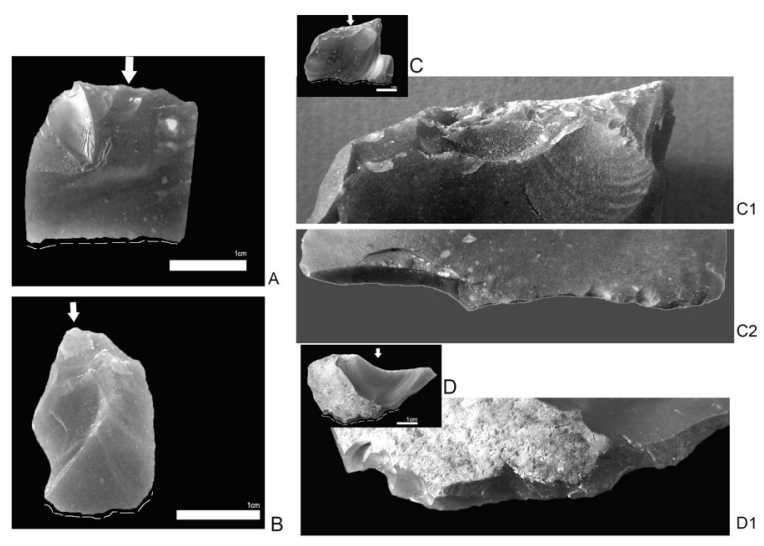

Fig. 14. Piezas experimentales para abrir en dos costillas de bóvido (signos explicados en Fig. 11). Obsérvese de nuevo el desarrollo limitado de los desconchados, en los casos A y B no son visibles sin ayuda de la lupa binocular y en C2 su desarrollo es irregular y se intercala con fracturas (fotografías Paloma de la Peña).

desconchados (pequeños y de extensión marginal). En las restantes se han producido únicamente pequeñas fracturas. Este experimento tampoco genera morfologías tipo retoque astillado en el filo activo.
La experimentación con madera de Buxus sempervirens y piezas intermedias a modo de cuña no funcionó y apenas se incidió en la madera. Toda esta variante experimental de 'abrir troncos' se realizó con maderas sumergidas en agua durante, al menos, un día. Del filo directamente percutido saltaban abundantes esquirlas producto de la fuerte percusión y de la gran resistencia ofrecida por esta especie (Fig. 16A y A1). En cambio, el filo activo, se embotaba rápidamente y la pieza no trabajaba (Fig. 16A2). Las piezas seleccionadas fueron de un tamaño considerablemente mayor que el empleado con las ramas, con el fin de evitar su rápida fracturación. Se primó en la elección de soportes las lascas o restos de talla con un filo activo agudo y al mismo tiempo robusto. Los desconchados que se generaron en el filo activo eran de tamaño medio y, ocasionalmente, grande (Tab. 1). Su extensión, en algunos casos, llegó a ser invasora. Los desconchados se alternaban con la generación de pequeñas fracturas que impedían rápidamente que la cuña siguiese activa. Estos desconchados del filo activo tampoco se pueden identificar con el retoque astillado.

La experimentación con el resto de tipos de madera fue también muy poco efectiva. Tan sólo se pudo abrir un tronco de Carpinus betulus tras haberlo sumergido en agua varios días. La cuña que lo abrió no presentaba desconchados a simple vista en el filo activo, por lo que se deduce que su zona de trabajo fueron los flancos (Fig. 16D y D1). Por otra parte, una gran cantidad de piezas se fracturaron, presentando características similares a las ya descritas para las ramas de menor tamaño (Fig. 16B2). La extensión y el tamaño de los desconchados eran menores que los observados durante el trabajo de madera de boj, y tampoco eran identificables como retoque astillado (Fig. 16C1).

\subsection{Trabajos de tipo cuña con asta}

La experimentación tuvo éxito, aunque el gasto de materia prima fue muy elevado. De los 23 soportes experimentales, sólo se pudieron seccionar tres pequeños trozos del asta. La actividad era especialmente 'agresiva' al acelerar el desgaste de la materia prima. Como en la talla bipolar el filo percutido y activo retrocedían rápidamente. Asimismo, saltaron abundantes restos de talla o astillas. 

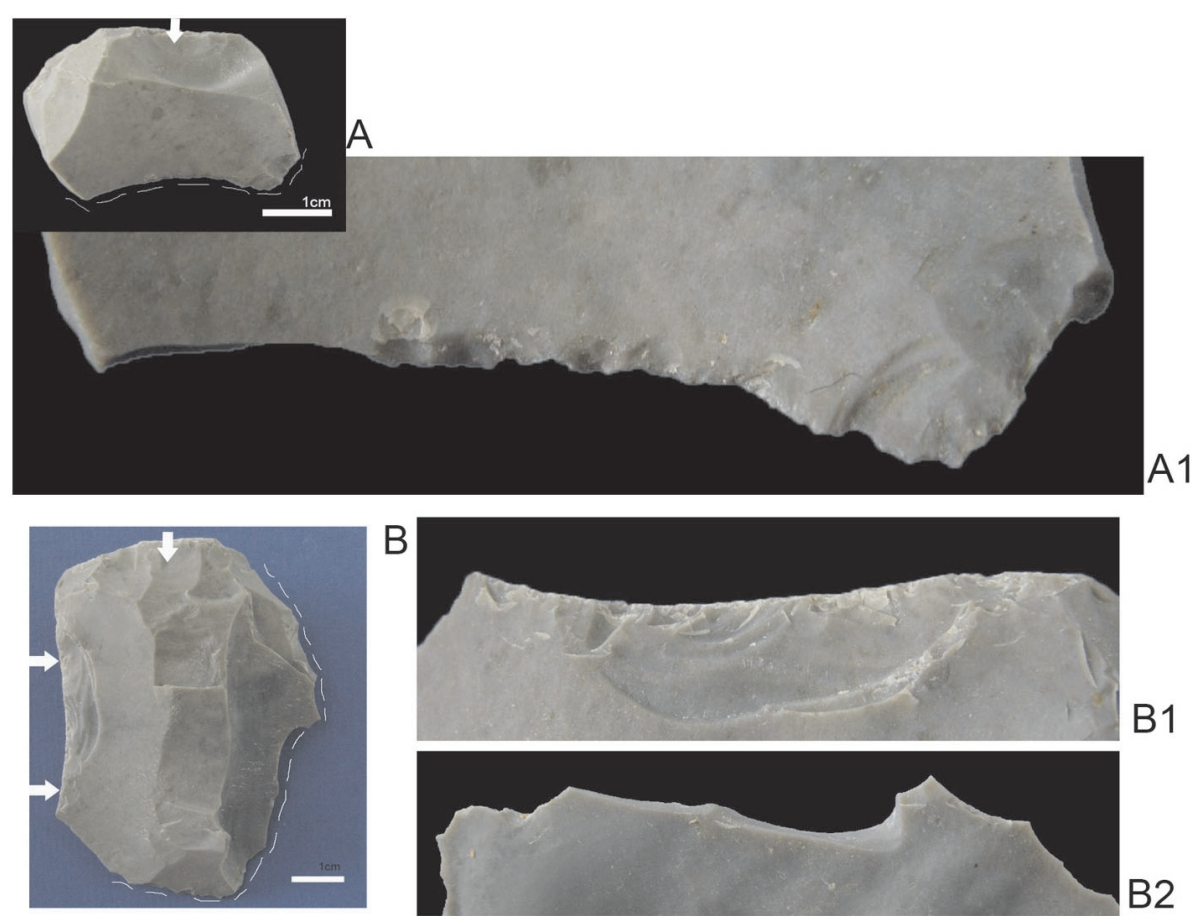

B1
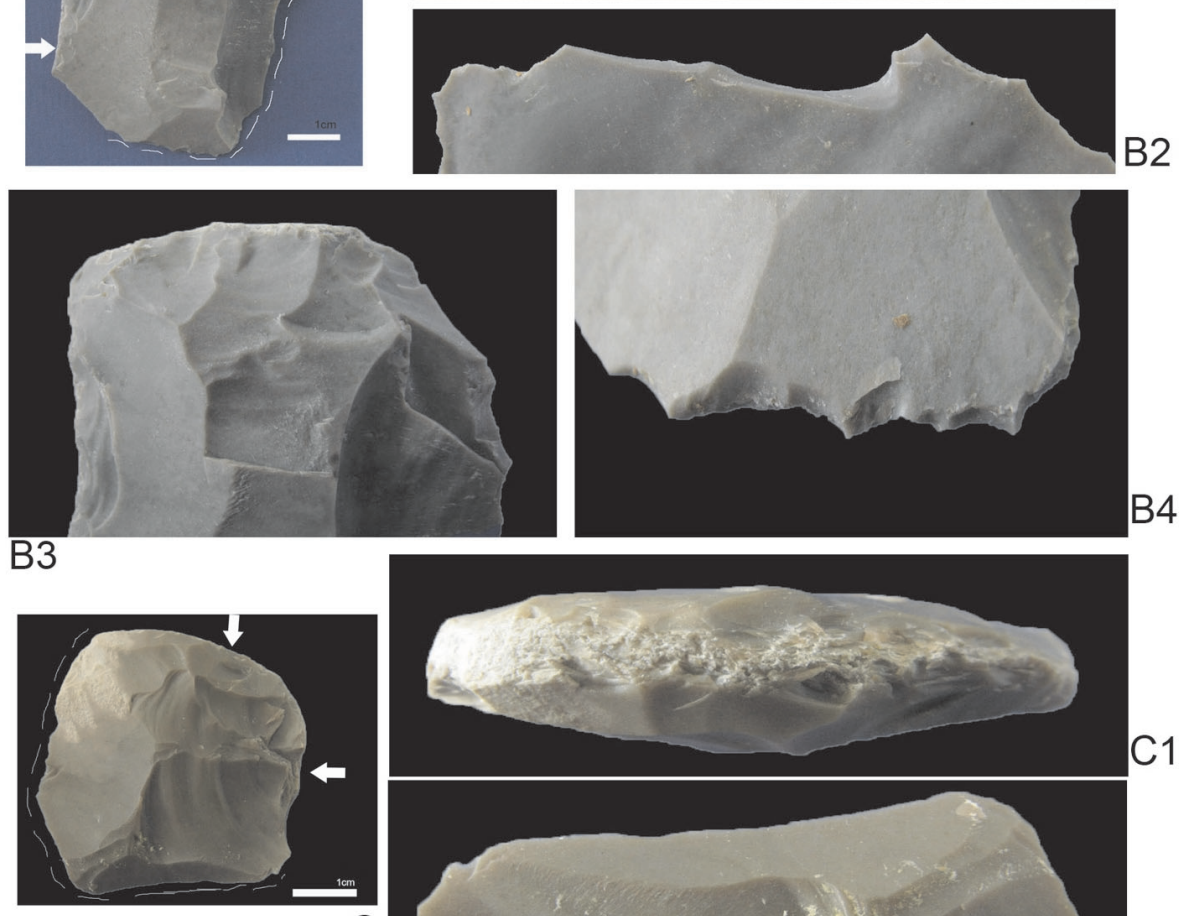

B4

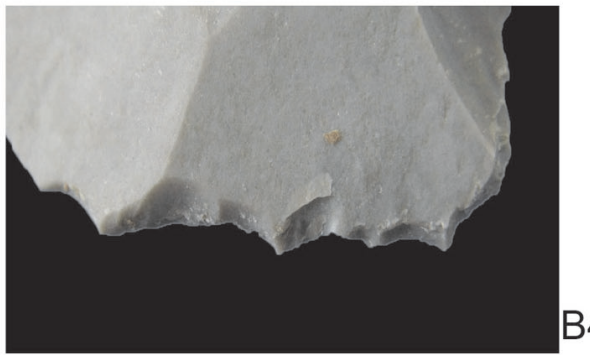

\section{B2}

C

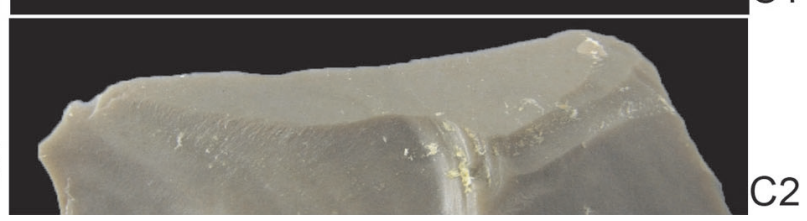

Fig. 15. Piezas experimentales intermedias empleadas para cortar ramas de diferentes especies (signos explicados en Fig. 11). Obsérvense las fracturas numerosas (B2), el desarrollo limitado de los desconchados en el filo activo (A1, B2, B4 y $\mathrm{C} 2$ ), contrastando con los filos percutidos ( $\mathrm{B} 1, \mathrm{~B} 3$ y $\mathrm{C} 1)$ en los que se consigna la fisuración y embotamiento de la percusión mineral (B1 y C1) (fotografías Paloma de la Peña).

Los principales rasgos registrados son el gran desarrollo en tamaño y extensión de desconchados en el filo activo, incluyendo fisuración (Fig. 17A2, C1 y D1), la delineación irregular del filo activo
(Fig. 17A2) y el carácter heterométrico (desigual) de los desconchados en el filo activo (Fig. 17D1).

Este trabajo sí generó en el filo activo morfologías de retoque astillado, si bien su delineación 

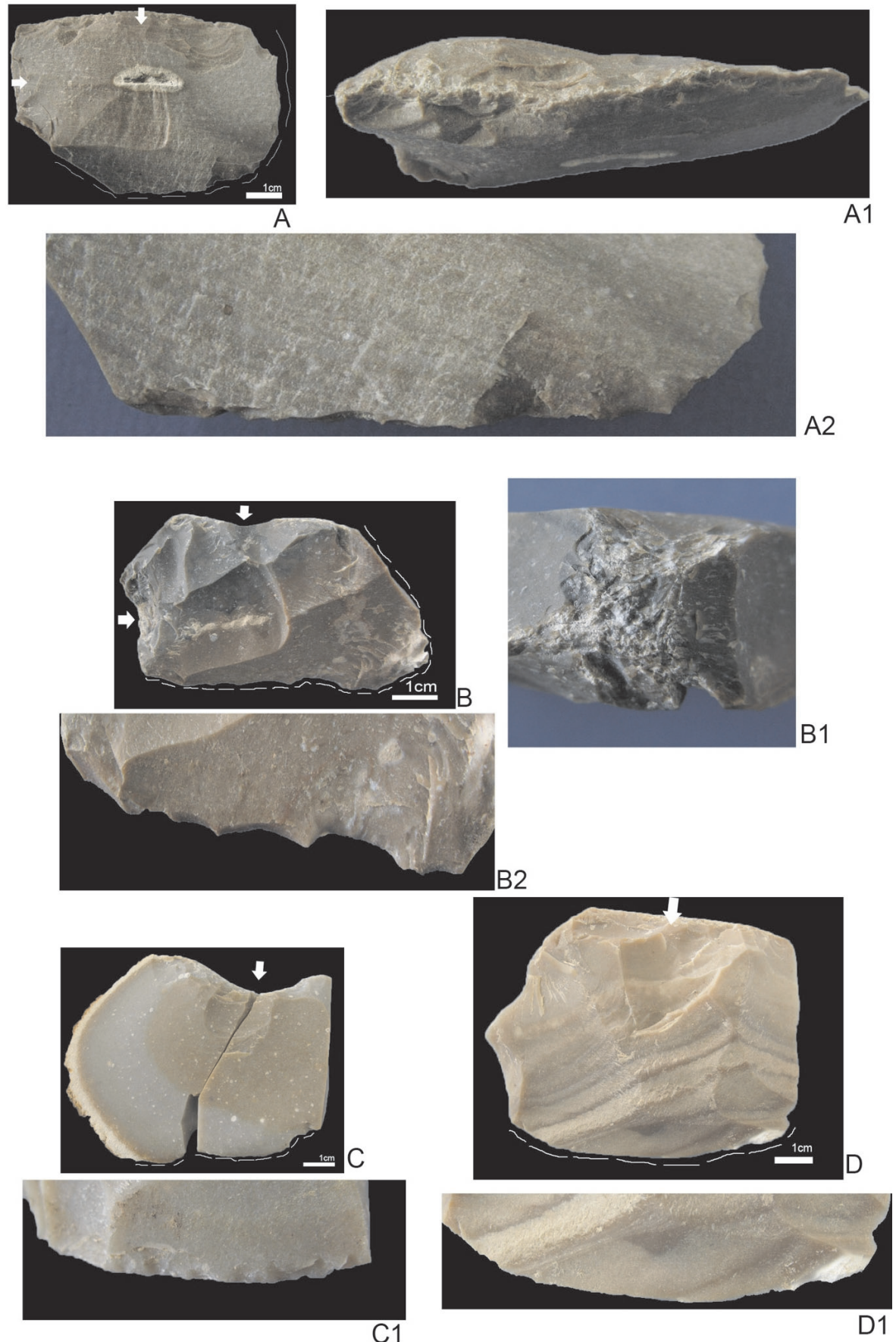

Fig. 16. Piezas experimentales como cuñas para abrir troncos (signos explicados en la Fig. 11). La pieza A fue utilizada con madera de boj, obsérvese el embotamiento del filo percutido (A1) y los desconchados irregulares del filo activo (A2). Las piezas $\mathrm{B}$ y $\mathrm{C}$ se emplearon con el resto de especies madereras. El filo percutido desarrolla numerosas extracciones $\mathrm{y}$ embotamiento (B1) y el filo activo fracturas (B2), pequeños desconchados (C1) e, incluso, puede quedar intacto (D1), ya que el trabajo lo realizan realmente los flancos de la cuña (fotografías Paloma de la Peña). 

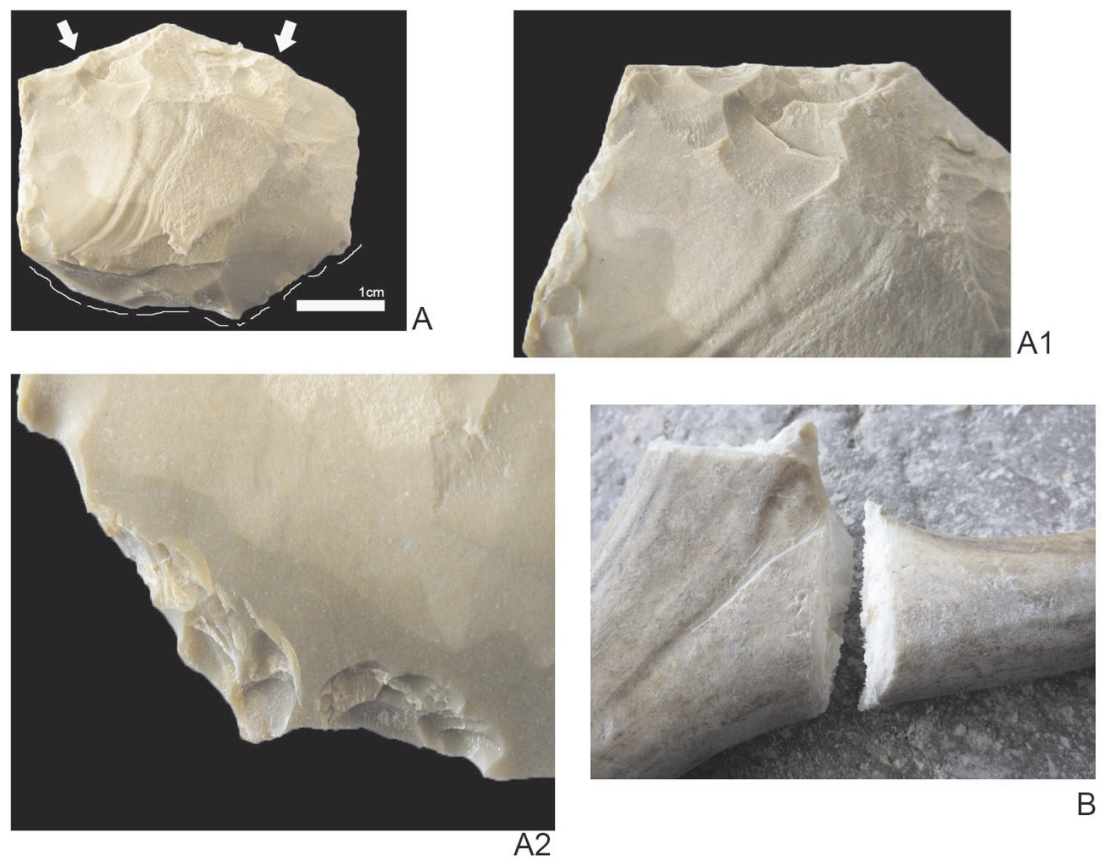

B
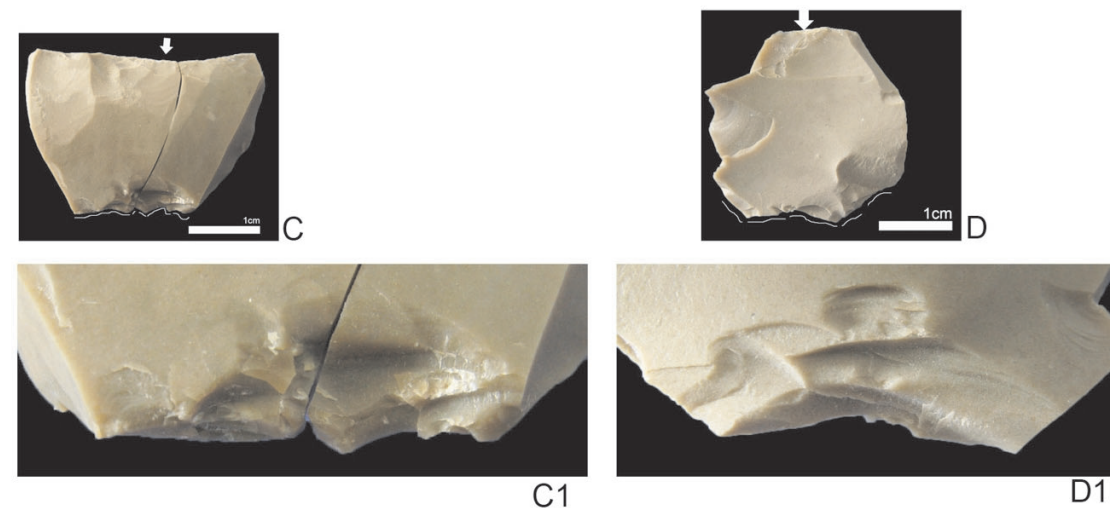

Fig. 17. Piezas experimentales empleadas como cuñas para cortar segmentos de asta (signos explicados en la Fig. 11). Obsérvese el desarrollo rectilíneo del filo percutido (A1) e irregular del activo (A2, C1 y D1) (fotografías Paloma de la Peña).

quedó siempre irregular y los desconchados tenían morfología y tamaños desiguales.

\section{CONCLUSIONES}

Como se ha visto, las morfologías obtenidas en los filos percutidos directamente, en la talla bipolar y empleando cuñas son prácticamente idénticas, dificultando su posible distinción. Sin embargo, los diferentes trabajos propuestos, según se ha demostrado en esta experimentación, modifican la morfología resultante en el filo durmien- te o activo. Además, no todos los experimentos con empleo de cuñas han generado desconchados identificables con el denominado retoque astillado.

Paradójicamente, la principal característica de la talla bipolar es que produce siempre lo que tipológicamente se denominan piezas astilladas de morfología cuadrangular o rectangular con dos o más filos opuestos con retoque astillado. En este caso las extracciones entre el filo percutido y el durmiente desarrollan una morfología simétrica. Los principales estigmas para reconocer este método de talla son los descritos más arriba, unidos 
a la producción del principal objetivo de la talla: las astillas. En otras palabras, en un conjunto con un método de talla bipolar no sólo se encontrarán las piezas astilladas sino también las astillas y los elementos imprescindibles para practicarlo, como percutores y yunques con estigmas lineales y formación de cúpulas o cazoletas.

La mayor parte de los trabajos con aplicación de cuña no han resultado en filos activos con morfologías identificables con el retoque astillado. Incluso el desarrollo de los desconchados puede ser marginal o anecdótico, en contra de lo que algunos estudios anteriores habían propuesto. En este sentido, han sido especialmente reveladoras las experiencias con madera y, en determinados casos, hueso. Además es frecuente que estos desconchados vayan acompañados de fracturas. Los trabajos de tipo cuña que sí producen un astillamiento del filo activo -relacionados con la acción sobre los materiales más duros, como el corte de huesos largos o asta-suelen ir acompañados de la creación de filos de delineación irregular con grandes extracciones reflejadas y desiguales (heterométricas), cuyas características difieren de las vistas para el filo durmiente de la talla bipolar, tendente a la regularización y al carácter rectilíneo. Es decir, en este tipo de piezas, el astillamiento de los dos filos opuestos no resultaría en una morfología simétrica, como en los núcleos bipolares (Tab. 2).

En suma, si en un conjunto arqueológico se conservaran piezas astilladas enteras, se podría llegar a distinguir a que variante responden atendiendo a todos los elementos expuestos dentro de una serie amplia, comparando las características específicas de las extracciones/desconchados, su densidad, extensión y la delineación de los filos.

Esta propuesta experimental parece haber puesto de manifiesto que muchos problemas tecno-tipológicos deberían buscar su solución en planteamientos funcionales.

\section{AGRADECIMIENTOS}

Esta experimentación tuvo lugar durante mi estancia como becaria predoctoral FPU en el $L a-$ boratoire Méditerranéen de Préhistoire EuropeAfrique (LAMPEA) de la Maison Méditerranéenne des Sciences de l'Homme en Aix-en-Provence en el otoño 2008. El Dr. Hugues Plisson me facilitó toda la ayuda durante la misma, así como el

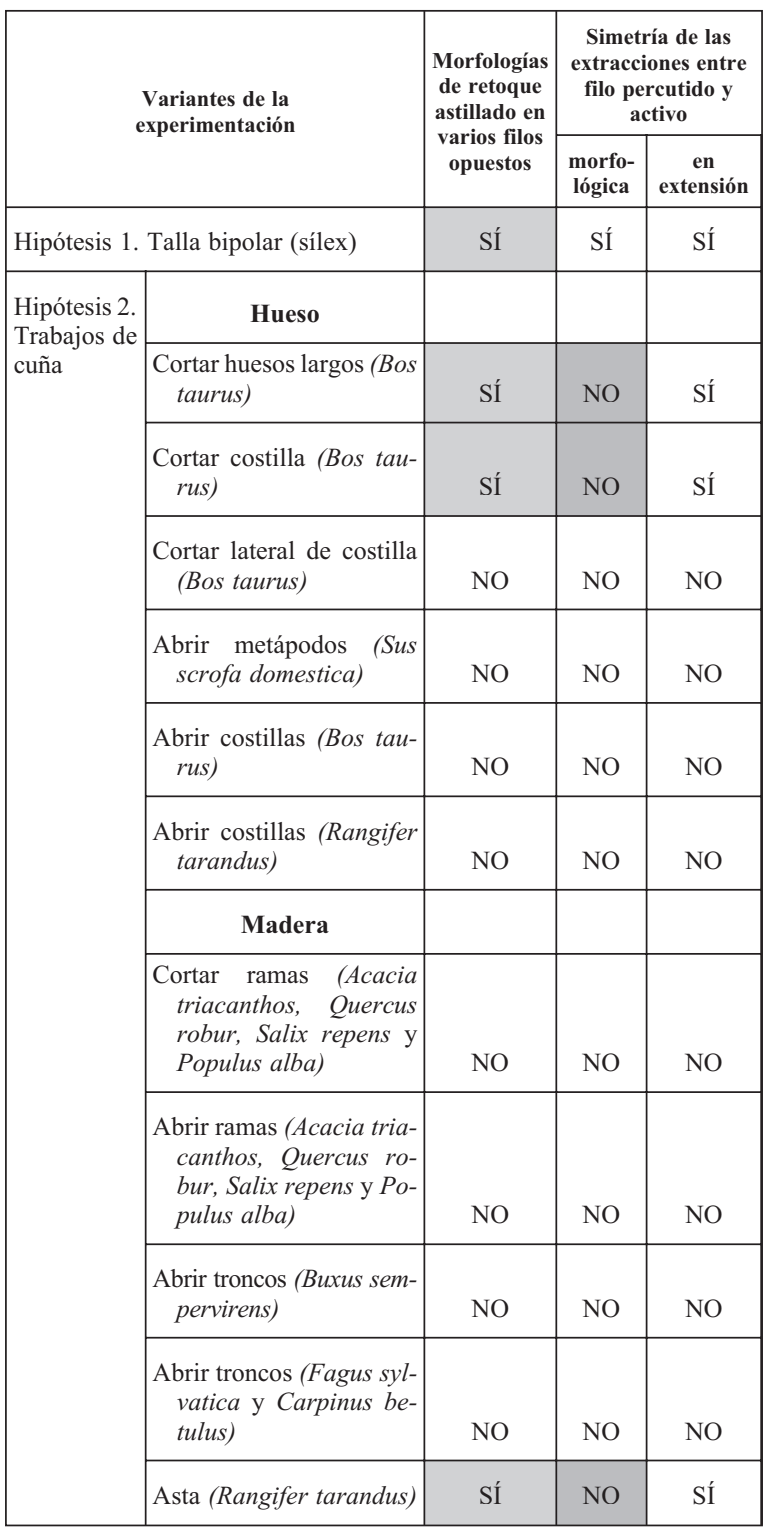

Tab. 2. Características morfológicas de los trabajos planteados. Se han señalado en gris claro los que generan lo que tipológicamente se define como "retoque astillado". Obsérvese que en todas las actividades de tipo cuña que lo produjeron no existe simetría morfológica entre los desconchados de los filos opuestos (casillas marcadas en gris más oscuro) y la delineación del filo activo es irregular. Ello permite diferenciarla de la talla bipolar.

equipo de traceólogos e investigadores del laboratorio. En especial he de recordar a Aliette Lompré, Amaranta Pasquini, Laure Metz, Ludovic Slimak, Aude Coudenneau y Dominique Commelin. Agradezco la relectura del manuscrito y los buenos consejos al Dr. Marc Tiffagom, 
Dr. L. Gerardo Vega, Fernando Colino, Pilar Alonso, Eduardo de la Peña, así como la revisión de los dos correctores anónimos y de los editores de la revista Trabajos de Prehistoria, que han sugerido numerosos cambios en pro de mejorar mi propuesta inicial.

\section{BIBLIOGRAFÍA}

Aubry, T.; Zilhão, J.; Almeida, F. y Fontugne, M. 1998: "Production d'armatures microlithiques pendant le Paléolithique supérieur et le Mesólithique au Portugal”. En R. Balbín y P. Bueno (eds.): II Congreso de Arqueología peninsular (Zamora, 1996): 259-272, Zamora.

Bardon, L.; Bouyssonie, J. y Bouyssonie, A. 1906: "Outils écaillés par percussion". Revue de l'Ecole d'Anthropologie 16: 170-175.

Binford, L. y Quimby, I. 1963: "Indian sites and chipped stone materials in the northern lake Michigan area". Field indiana anthropology 36 (12): 277-307.

Bordes, F. 1970: "Réflexions sur le outils au Paléolithique". Bulletin de la Societé Préhistorique Française 67 (7): 199-202.

Brézillon, M. N. 1971: La dénomination des objets de pierre taillée. Máteriaux pour une vocabulaire du langue française. IV Supplement Gallia Préhistoria, CNRS. Paris.

Cabanilles, J. J. 2008: El utillaje de piedra tallada en la Prehistoria reciente valenciana. Aspectos tipológicos, estilísticos y evolutivos. Serie de Trabajos Varios 109, Servicio de Investigación Prehistórica. Diputación de Valencia. Valencia.

Cattin, M.-I. 2002: Hauterive-Champréveyres 13. Un campement magdalénien au bord du lac Neuchâtel: explotation du silex (secteur 1). Archéologie neuchâteloise 26, 1. Neuchâtel.

Clottes, J. y Delporte, H. 2003: La grotte de La Vache (Ariège): Fouilles Romain Robert. 1: Les Occupations du Magdalénien. CTHS/RMN. París.

Chauchat, C.; Normand, C.; Raynal, J.-P. y Santamaría, S. 1985: "Le retour de la pièce esquillée!". $B u-$ lletin de la Societé Préhistorique Française 82: $35-41$.

Díez-Martín, F.; Sánchez, P.; Domínguez-Rodrigo, M. y Barba, R. 2009: "Were olduvai Hominins making butchering tools or battering tools? Analysis of a recently excavated lithic assemblage from BK (Bed II, Olduvai Gorge, Tanzania)". Journal of Anthropological Archaeology, 28: 274-289.

Donnart, K.; Naudinot, N. y Le Clézio, L. 2009: "Approche expérimentale du débitage bipolaire sur enclume: caractérisation des produits et analyse des outils de production". Bulletin de la Societé Préhistorique Française 106 (3): 517-533.

Escalon de Fonton, M. (1969): "La pièce esquillée. Essai d'interpretation". Bulletin de la Societé Préhistorique Française 66 (1): 76.

Fagnart, J.-P. y Plisson, H. 1994: "Fonction des pièces mânchurées du Paléolithique Final du Bassin de la Somme: caractères tracéologiques et données contextuelles". En J.-P. Fagnart y A. Thévenin (eds.): Chronostratigraphie et environnement des occupations humaines du Tardiglaciare et du début de l'Holocène en Europe du Nord-Ouest. 119 Congrès National de Société historique et scientifique, CTHS. Paris: 95-106.

Fischer, A.; Vemming Hansen, P. y Rasmussen, P. 1984: "Macro and Micro wear Traces on lithic Projectile Points. Experimental Results and Prehistoric Examples". Journal of Danish Archaeology 3: 19-46.

Furestier, R. 2005: Les industries lithiques campaniformes du sud-est de la France. Universite de Aix-Marseille I. Aix-en-Provence. http://tel.archives-ouvertes.fr/tel-00084729/en/ (consulta 8-IV-2011).

Gibaja, J. F. y Bicho, N. F. 2006: "La función de los instrumentos líticos en el Asentamiento de Vale Boi (Algarve, Portugal). Estudio del utillaje gravetiense y solutrense". Saguntum 38: 9-21.

Gibaja, J. F.; Palomo, A.; Bicho, N. F. y Terradas, X. 2007: "Tecnología y función de los 'útiles astillados': Programa experimental para contextos prehistóricos de la Península Ibérica”. En M. L. Ramos, J. E. González Urquijo y J. Baena (eds.): I Congreso Español de Arqueología experimental en la Península Ibérica (Santander 2005): 157-164. Santander.

González Urquijo, J. E. e Ibáñez, J. J. 1994: Metodología de análisis funcional de instrumentos tallados en silex. Universidad de Deusto. Bilbao.

Goodyear, A. C. 1993: "Tool Kit entropy and bipolar reduction: a study of interassemblage lithic variability among Paleo-Indian sites in the Northeastern United States". North American Archaeologists 14 (1): $1-23$.

Guyodo, J.-N. y Marchand, G. 2005: "La percussion bipolaire sur enclume dans l'Ouest de la France de la fin du Paléolithique au Chalcolithique: une lecture économique et sociale". Bulletin de la Societé Préhistorique Française 102 (3): 539-549.

Hayden, B. 1980: "Confusion in the bipolar world: bashed pebbles and splintered pieces". Lithic Technology 9 (1): 2-7.

Laplace, G. 1972: La Typologie analythique et structurale: base rationnelle d'étude des industries lithiques et osseuses. Colloques nationaux du centre National de la Recherche Scientifique 932, Banques de donnes archéologiques. Marsella. 
Leblanc, R. 1992: "Wedges, pieces esquilees, bipolar cores, and other things: an alternative to Shott's view of bipolar industries". North American Archaeologists 13 (1): 1-14.

Le Brun-Ricalens, F. 1989: “Contribution à l'étude des pièces esquillées: la présence de percuteurs à 'cupules"'. Bulletin de la Societé Préhistorique Française 86 (7): 196-200.

Le Brun-Ricalens, F. 2006: "Les pièces esquillées: état des connaissances après un siècle de reconnaissance". Paleo 18: 95-114.

Leesch, D. 1997: Hauterives-Champréveyres. Un campément magdalénien au bord du lac de Neuchâtel: cadre chronologique et cultural, mobilier et structures, analyse spatial (Secteur 1). Archéologie neuchâteloise 19. Neuchâtel.

Lucas, G. y Hays, M. 2004: Les pièces esquillées du site paléolithique du Flageolet I (Dordogne): outils ou nucléus?, XXV Congrès Préhistorique de France. Approches fonctionnelles en Préhistoire (Nanterre, 2000): 107-120. París.

Mazière, G. 1984: "La pièce esquillée, outil ou déchet?" Bulletin de la Societé Préhistorique Française 81 (6): 182-187.

Mourre, V. 1996: Le débitage sur enclume au Paléolithique inférieur et moyen. Techniques, méthodes et schemas conceptuels. DEA, Paris X. París. http://vincent.mourre.free.fr/textes/Mourre_DEA 1996.pdf (consulta 8-IV-2011)

Mourre, V. 2004: "Le debitage sur enclume au Paléolithique Moyen dans le Sud-Ouest de la France". En P. Van Peer, D. Bonjean y P. Semal (eds.): Session 5: Paléolithique moyen. Actes du XIVème Congrès de l'UISPP, Liège, 2001. British Archaeological Reports, International Series 1239. Archaeopress. Oxford: 29-38.

Octobon, C. 1938: “Contribution à l'étude des outillages. Ciseaux et pièces esquillées". Bulletin de la
Societé Préhistorique Française XXV, 101: 409412.

Patterson, L. W. y Sollberger, J. B. 1976: "The mith of bipolar flaking industries". Lithic Technology 5 (3): 40-42.

Rodríguez, A. 1993: 'L'Analyse fonctionelle de l'industrie du gisement epipaleolithique/mesolithique du Roc de Migdia (Catalogne, Espagne). Resultats preliminaires". Préhistoire Européenne 4: 63-84.

Semenov, S. A. 1964: Prehistoric lithic technology: an experimental study of the oldest tools and artefacts from traces of manufacture and wear. Cory, Adams et Mackay. Londres.

Shott, M. 1989: "Bipolar industries: ethnographic evidence and archaeological implications". North American Archaeologists 10 (1): 1-24.

Sonneville-Bordes, D. de y Perrot, J. 1956: Lexique typologique du Paléolithique supérieur. Bulletin de la Societé Préhistorique Française 53 (9): 547559.

Sonneville-Bordes, D. de (ed.) 1979: Actes du Colloque (Talence 1977). CNRS. París.

Tixier, J. 1963: Typologie de l'Epipaléolithique du Maghreb. Mémoires du Centre de recherches anthropologiques, préhistoriques et ethnographiques, Arts et Métiers graphiques. París.

Vaughan, P. C. 1985: Use war analysis of flake stone tools. The University of Arizona Press. Tucson.

White, P. 1968a: "Fabricators, Outils écaillés or Scalar Cores?". Mankind 6 (12): 658-666.

White, P. 1968b: "Stop Naip Bilonng Tumbuna: The living Stone Age in New Guinea". La Préhistoire. Problémes et tendences. Éditions du CNRS. París: 511-516.

Zilhão, J. 1997: O Paleolitico Superior da Estremadura Portuguesa. Ed. Colibri. Lisboa. 